\title{
الفروق في اتجاهات طلاب كلية التربية بجامعة بني سويف نحو \\ التعليم عن بعد والتقليدي والهجين في ظل جائحة كورونا
}

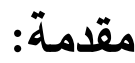

تلعب الاتجاهات دورا هاما في العملية التعليمية بجميع جوانها، حيث تؤثر انفعالات الطلاب واتجاهاتهم في تحقيقهم لأهدافهم الأكاديمية، فالتعلم المبني على دافعية الطلاب سـئيؤدي لجئي

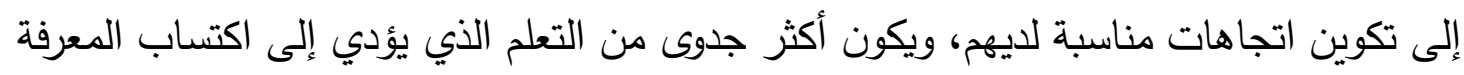

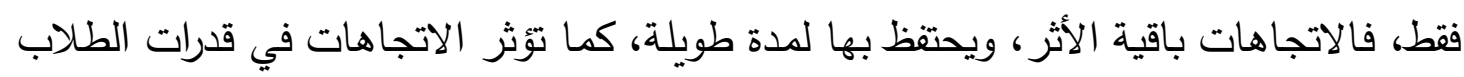

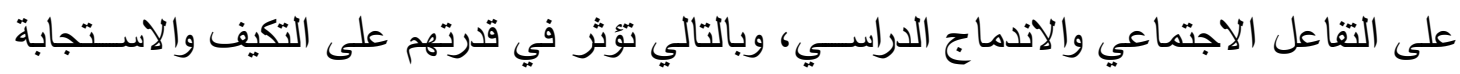

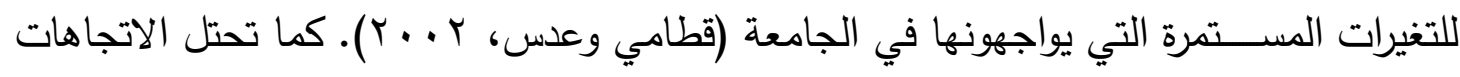

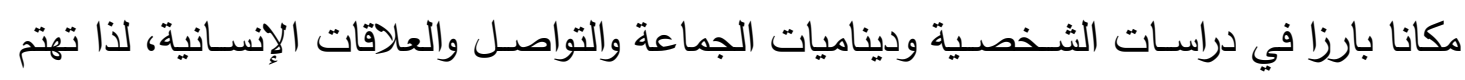
المؤسسات التربوية بدراسة الاتجاهات وتحليلها والتعرف على مكوناتها، ومراحلها وأساليب تكوينها وتعديلها، وذلك من أجل تطبيق تلك المعرفة وتوظيفها في تكوين الاتجاهات المرغوبة نحو الأفراد

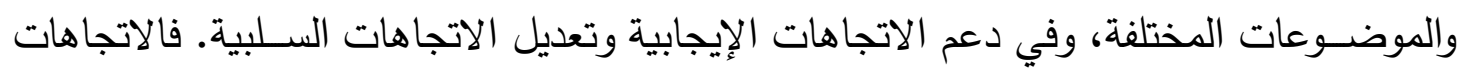

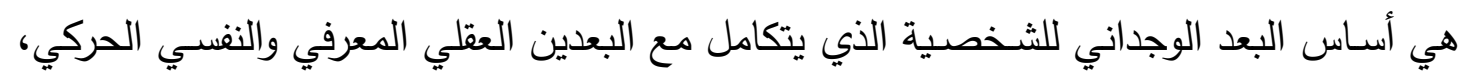

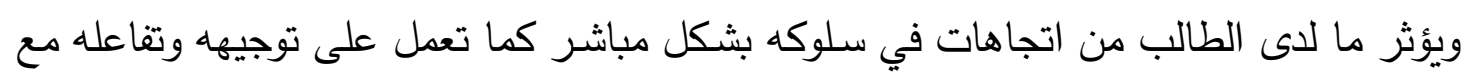

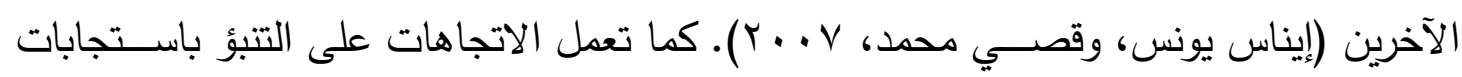
الطلاب لبعض المثيرات الاجتماعية، لذا حرصت المعاهد والكليات على مراعاة اتجاهات طلابها

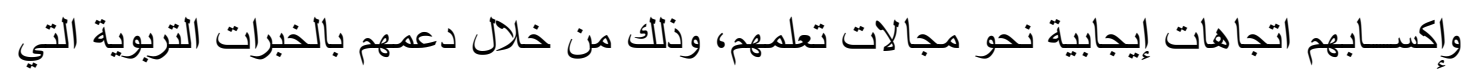

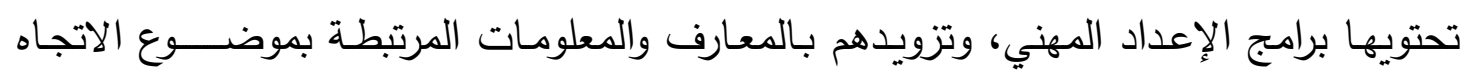
لمساعدتهم على إعادة ترتيب خبراتهم كلما اكتسبوا معارف جديدة (سيد خير الله، (191 ).

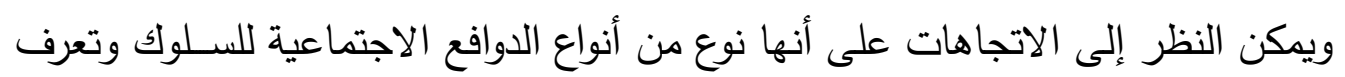

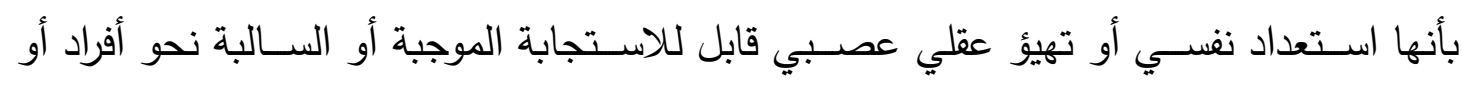
موضـوعات أو مواقف أو رموز في البيئة التي تستثير هذه الاستجابة (نواف أحمد، وعبدالسـلام

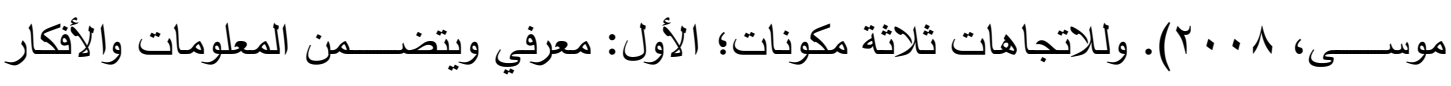
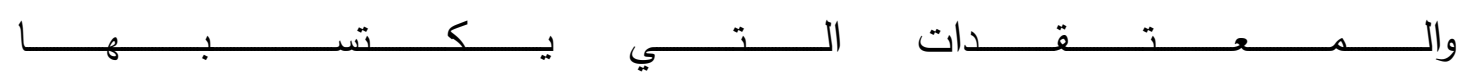

الطالب حول موضوع الاتجاه، والثاني: وجداني يعبر عن تأثره بموضوع الاتجاه والانفعال، بحيث

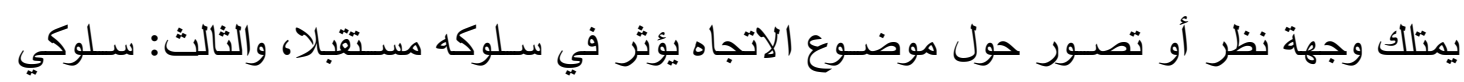

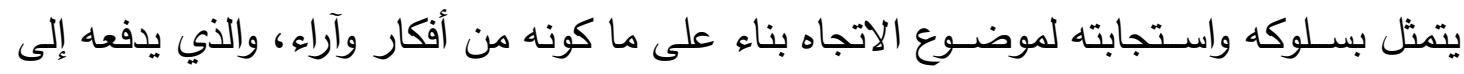


السلوك بأسلوب معين عند مواجهة موضوع الاتجاه (فيصل حميد، V . . Y). وتختلف الاتجاهات

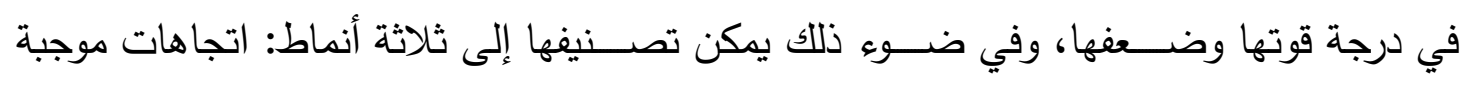

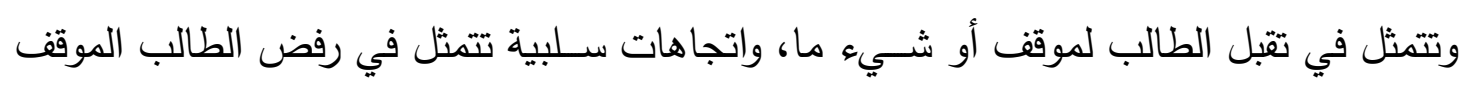

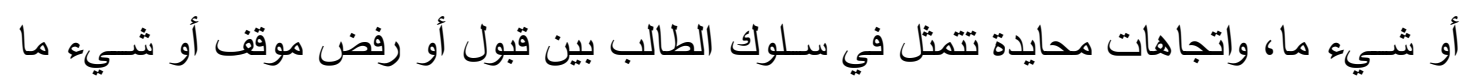

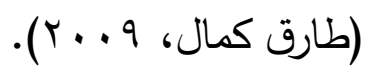

ومن جهة أخرى تمثل اتجاهات الطلاب عاملا هاما في بيئات التعلم المعتمدة على الكمبيوتر إلا

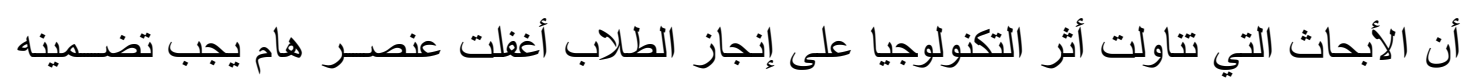

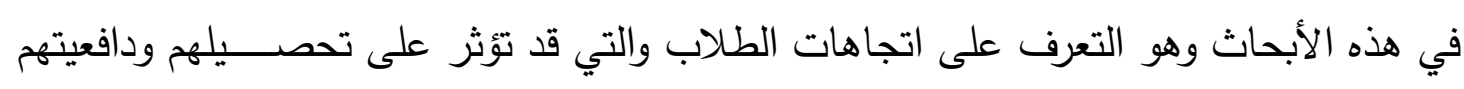

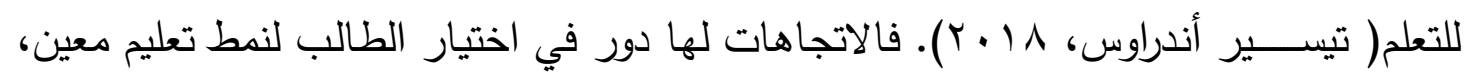
والتي تتعد في الوقت الحالي بين التعليم التقليدي، والتعليم عن بعد والتعليم الهجين.

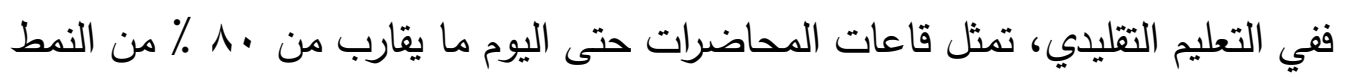

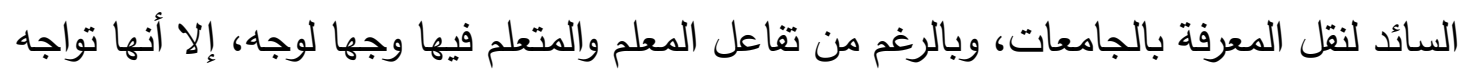

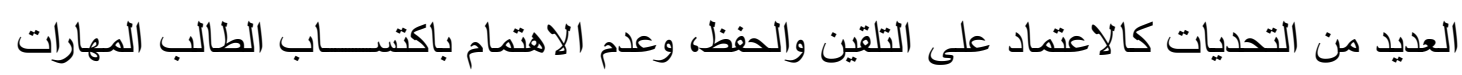
اللازمة للتعلم الذاتي، وكنلك ضعف الطاقة الاستيعابية والتجهيزات، وعدم القدرة على تلبية طموح

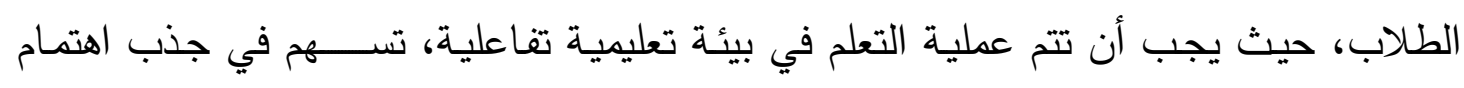

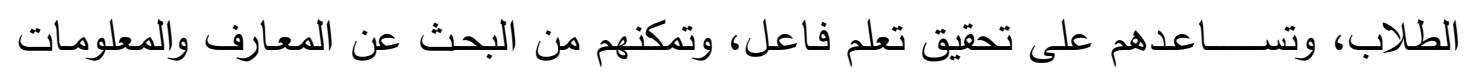

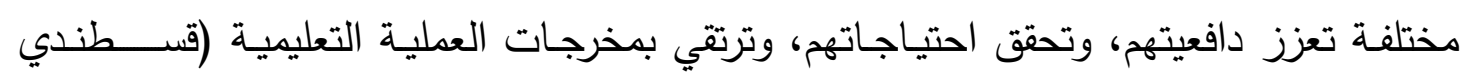

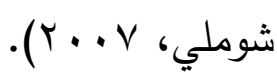
ومع التطورات التكنولوجية الحديثة، أصـبح على الجامعات الاسـتفادة منها وتوظيفها في لـاي

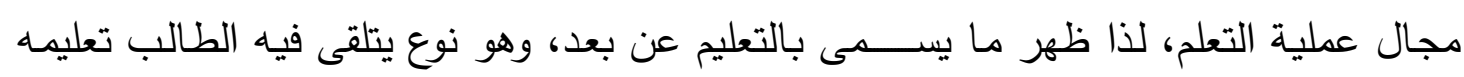

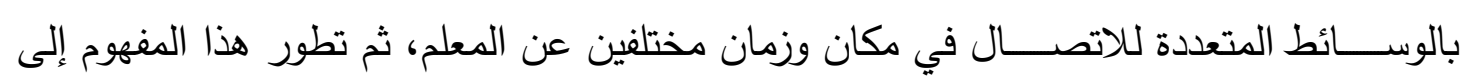

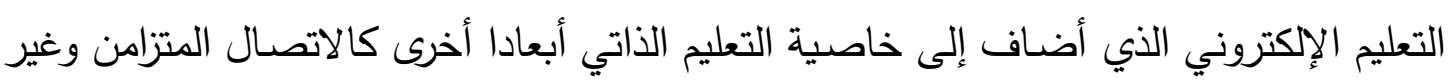

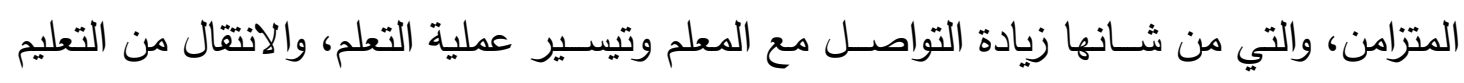
المتمركز حول المعلم إلى التعليم المتمركز حول المتعلم.

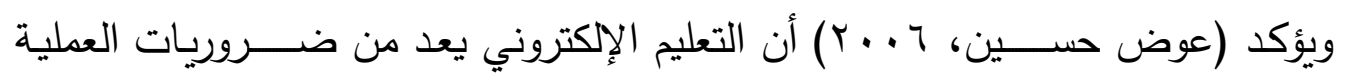

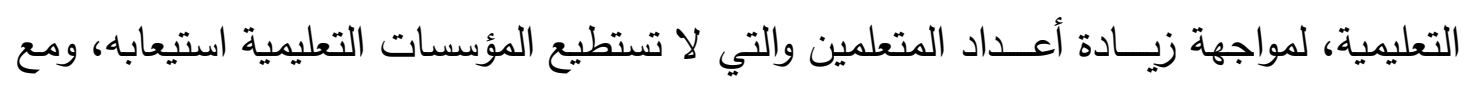
زيادة انتشار تطبيق التعليم الإكتروني في التعليم، ظهرت العديد من الصـعوبات التي تحد من فاعليته، ومنها

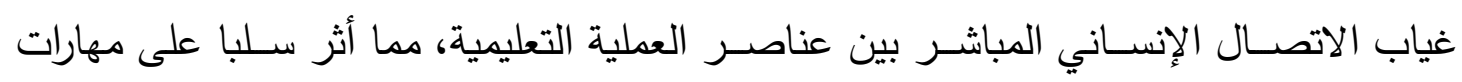

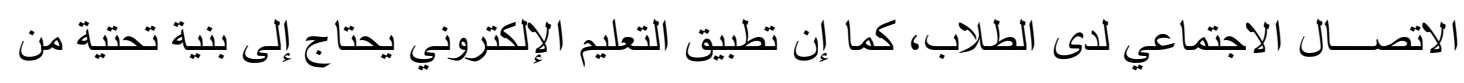


أجهزة ومعدات تتطلب تكلفة عالية، قد لا تتوافر في كثير من الأحيان لدى المؤسسـات التعليمية

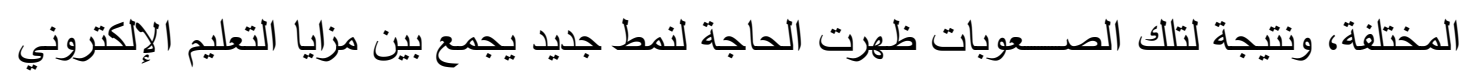

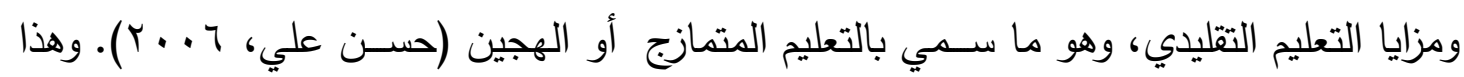

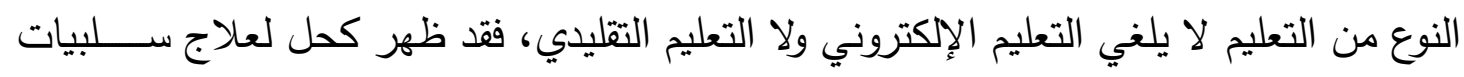

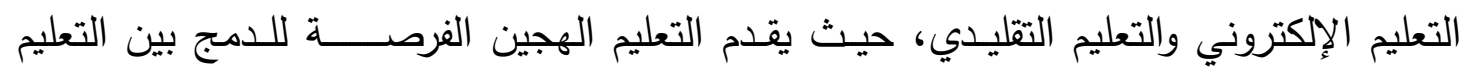

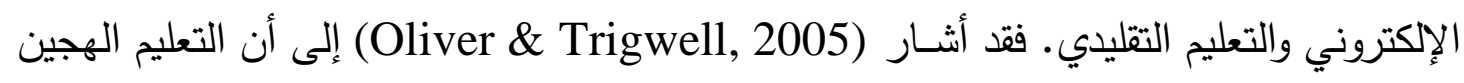

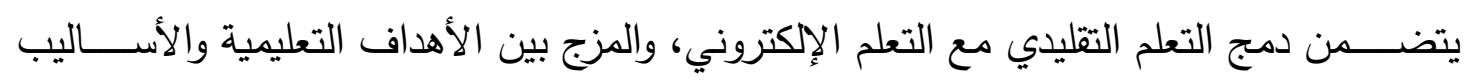

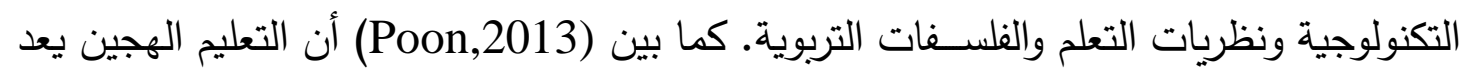

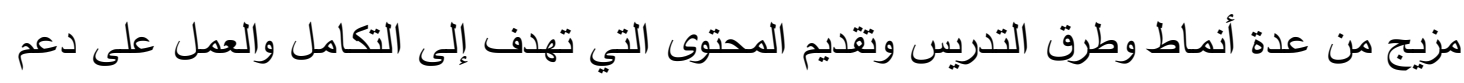
وتعزيز تعلم الطلاب.

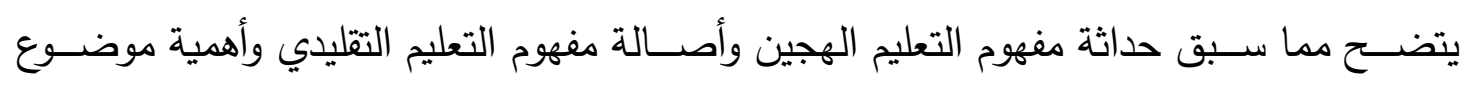

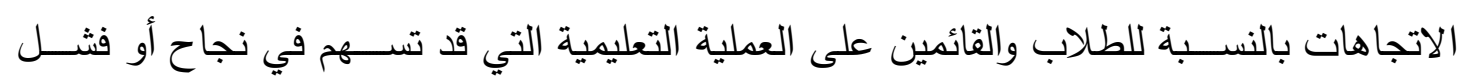

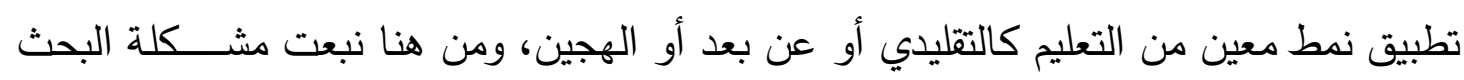
الحالي والتي يمكن صياغتها على النحو التالي:

\section{مشكلة البحث:}

إن البحث في اتجاهات الطلاب نحو اســـتخدام التعليم الإلكتروني من الأمور الهامة

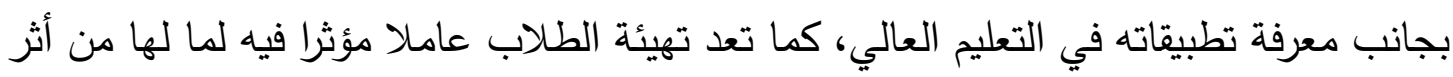

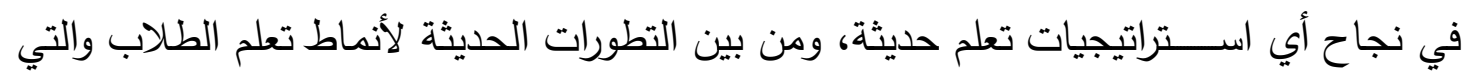

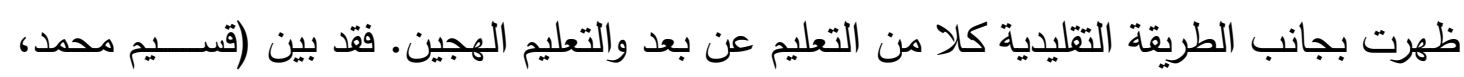

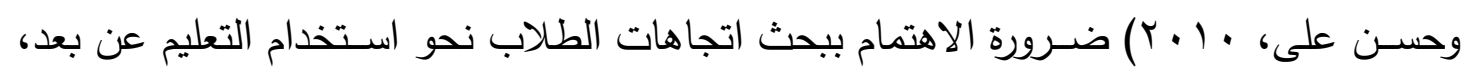

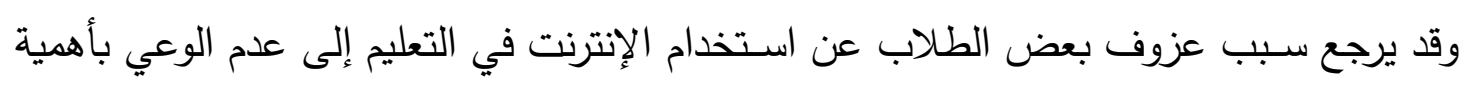

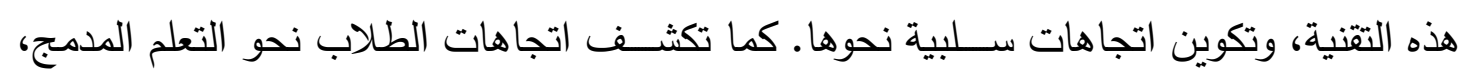

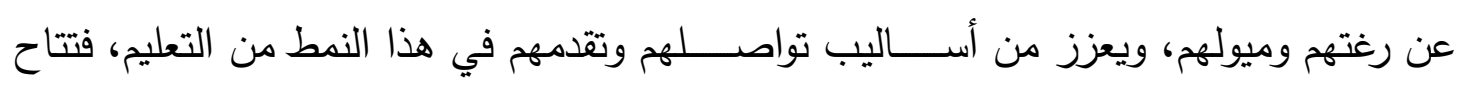
الفرصـة للمشاركة والاستماع والتفكير ، مما يؤدي إلى نمو جوانبهم المعرفية والمهارية والانفعالية،

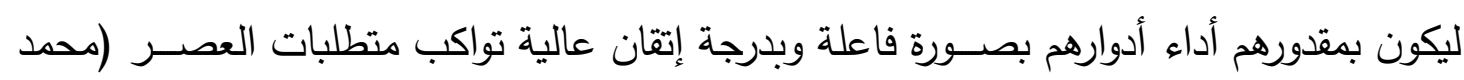


وفي التعلم المدمج يكون دور الطالب ليس مجرد حافظا للمعلومة وناقلا للمعرفة، وإنما

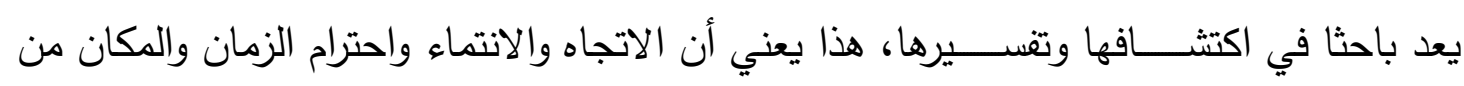

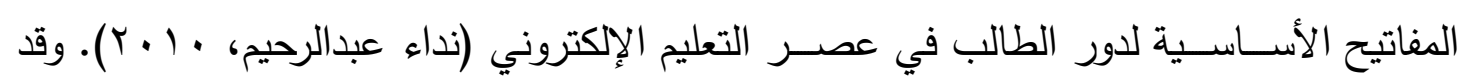

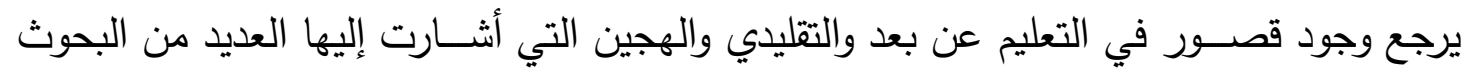

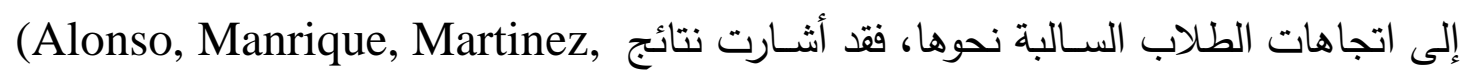
( \&ines, 2011)

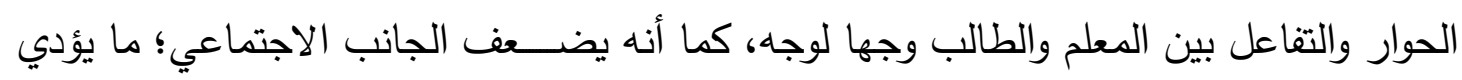

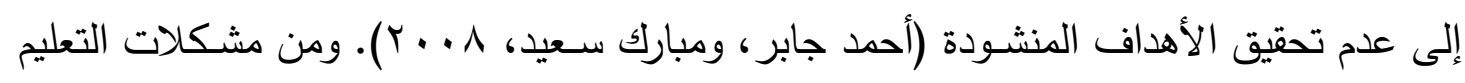

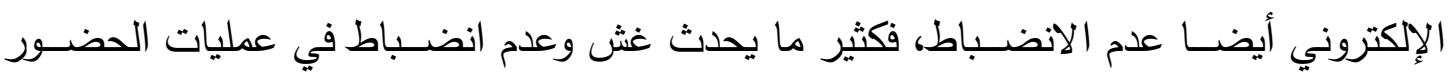
والامتحانات، كما أن الطلاب الذين تعلموا تعلما الكترونيا أقل كفاءة ومهارة في الحوار والقدان الطدرة

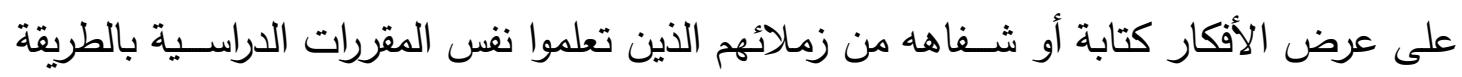

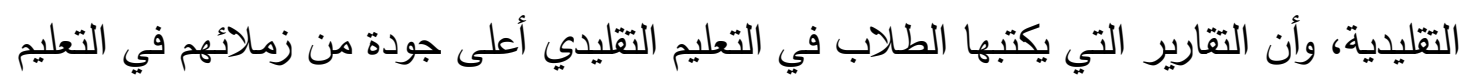

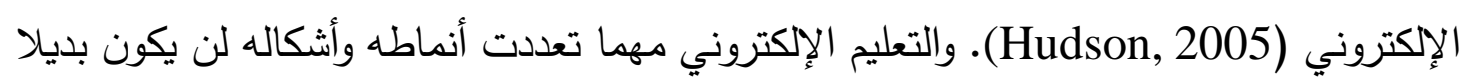

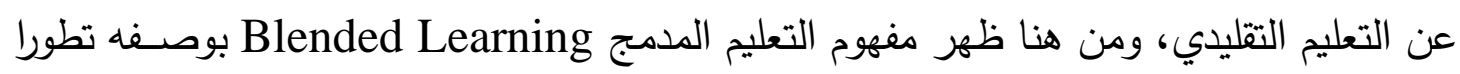

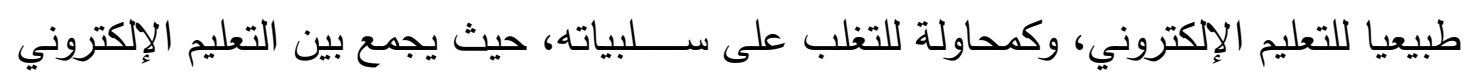

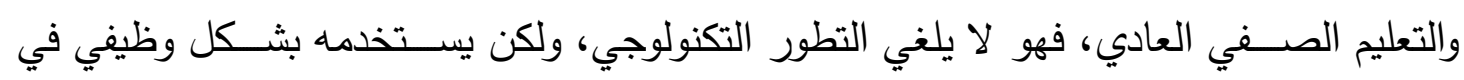

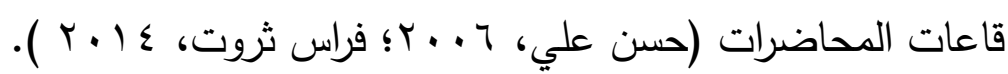
أوضــــ (Cameron, 2005) إيجابية التعليم الخليط في إثارة دافعية الطلاب للتعلم

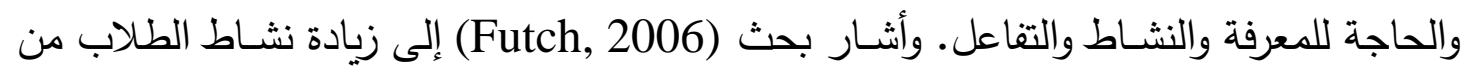

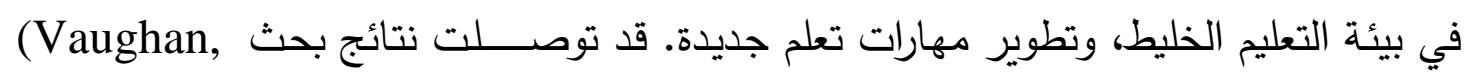

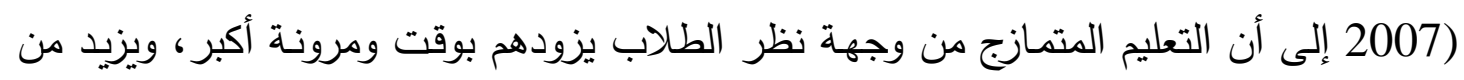

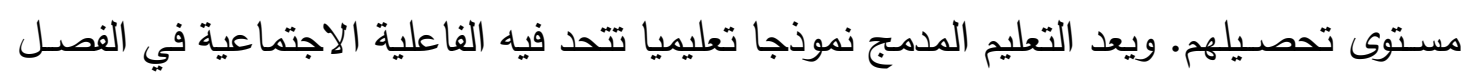

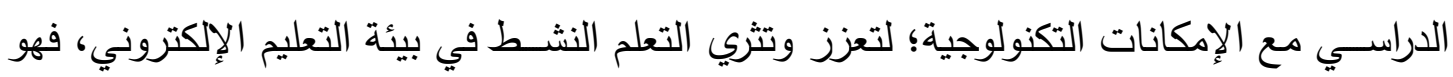
خليط من التفاعل الصفي التقليدي والتدريس الحي المباشر (John Watson, 2009).

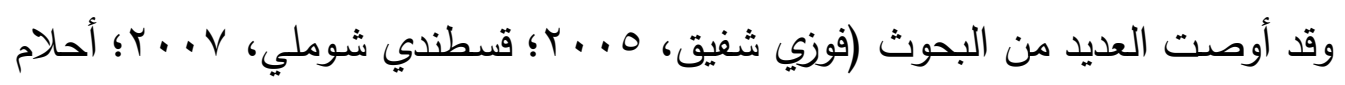

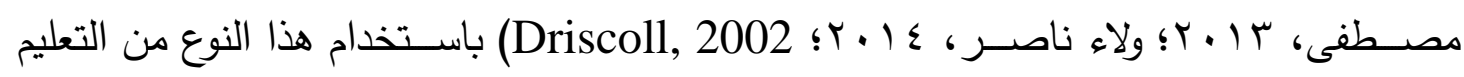

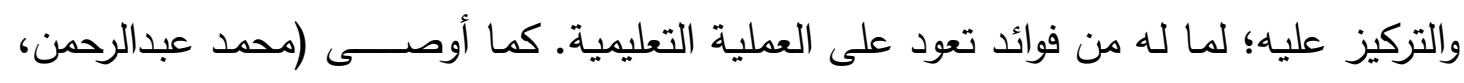

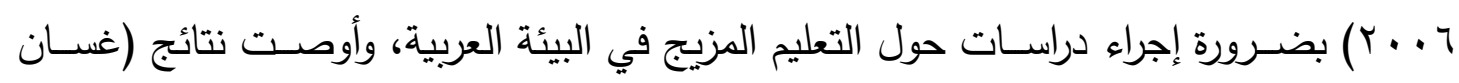

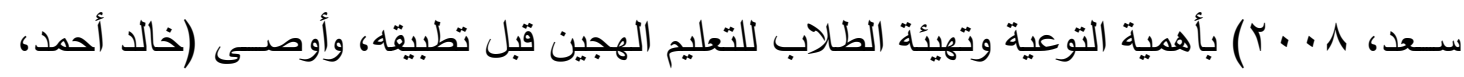




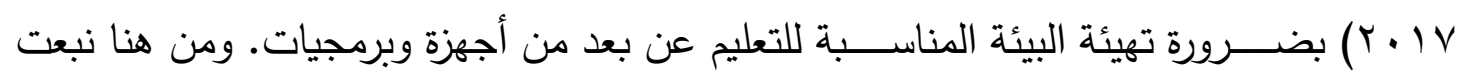
مشكلة البحث الحالي والتي تتحدد في الأسئلة التالية: السؤال الأول: ما اتجاهات عينة البحث نحو التعليم عن بعد والتقليدي والهجين؟.

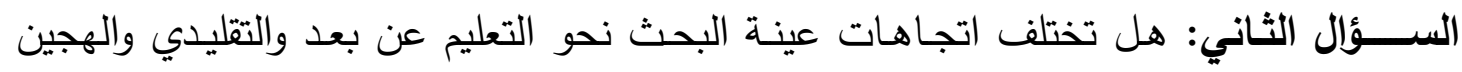
باختلاف: النوع والتخصص والفرق الدراسية؟ السؤال الثالث: هل تفضل عينة البحث أنماط التعليم عن بعد والتقليدي والهجين بنسب متساوية؟

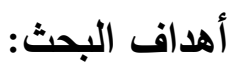
هدف البحث الحالي إلى التعرف على اتجاهات عينـة البحث نحو التعليم عن بعد والتقليدي

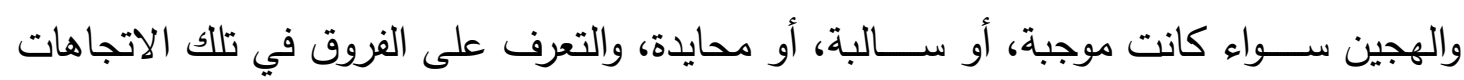

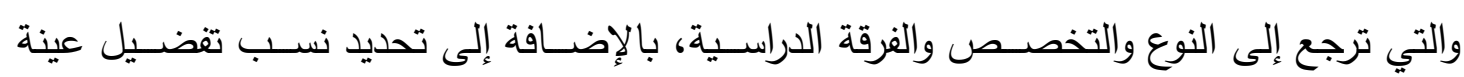
البحث لأي من التعليم عن بعد، أو التقليدي، أو الهجين.

أهمية البحث:

ترجع أهمية البحث الحالي إلى أن وزارة التعليم العالي والبحث العلمي تبنت في ظل الظروف

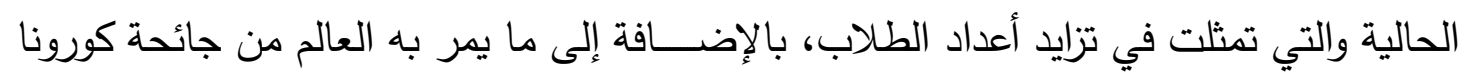

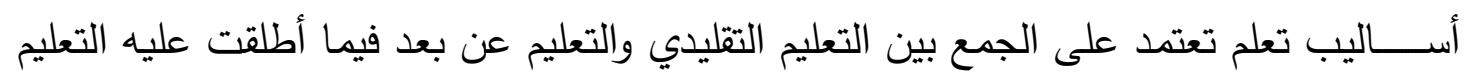

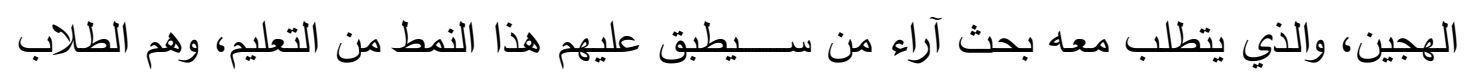

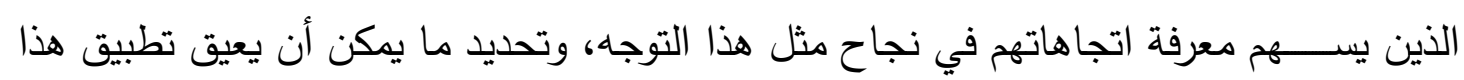

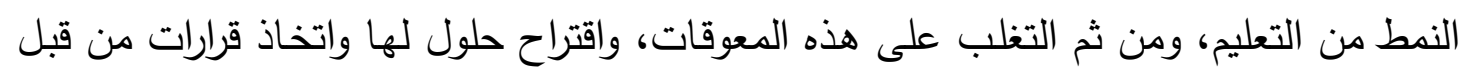
القائمين على صنع القرار بما يضمن استمراريته وفاعليته.

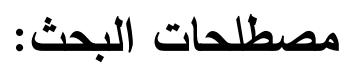

الاتجاهات:

أراء وتصـورات ومعتقدات ومشــاعر الطلاب نحو طريقة تعليمهم سـواء كانت تقليدية أو

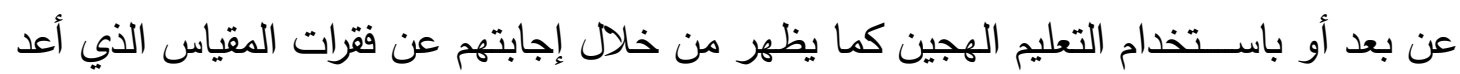
لهذا الغرض. 


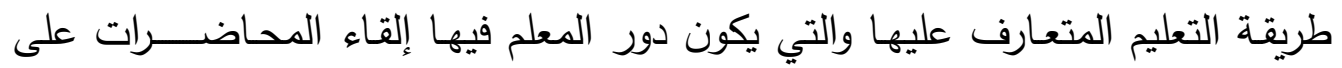
الطلاب باستخدام الوسائل التقليدية بينما يكون دور الطالب الاستماع والتلقي من المعلم.

\section{الاتجاه نحو التعليم التقليدي:}

مقدار أو شدة الانفعال التي يبديها أفراد العينة نحو التعليم التقليدي بالرفض أو القبول أو أو التئي

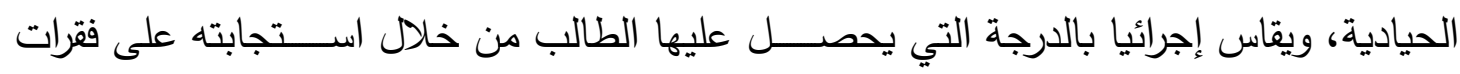

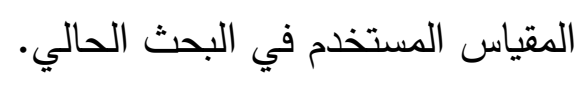

التعليم عن بعد:

إدارة عملية التعلم بكاملها، بما في ذلك تسجيل دخول الطلاب، وتتبع تقدمه، وتسجيل البيانات،

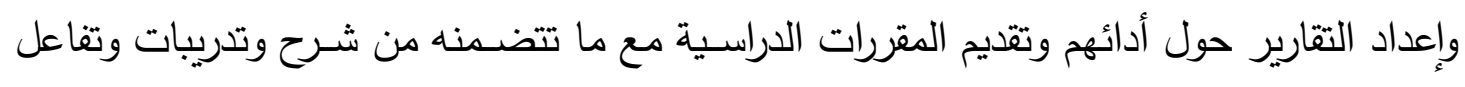
ومتابعة عن بعد باستخدام تقنيات المعلومات وشبكات الحاسوب لتدعيم العملية التعليمية وإثرائها

$$
\text { ورفع جودتها. }
$$

\section{الاتجاه نحو التعليم عن بعد:}

مقدار أو شدة الانفعال التي يبديها أفراد العينة نحو التعليم عن بعد بالرفض أو القبول أو أو التوات

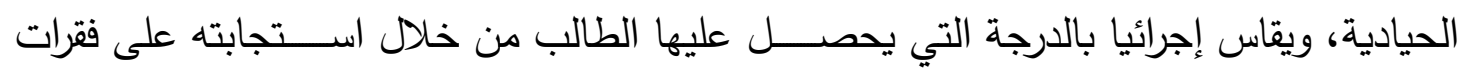

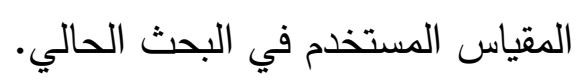

التعليم الهجين: - n

بيئة تعليمية تعلمية تتم من خلال توظيف المستحدثات التكنولوجية في الدمج بين كل من

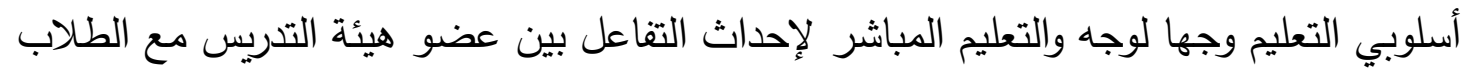

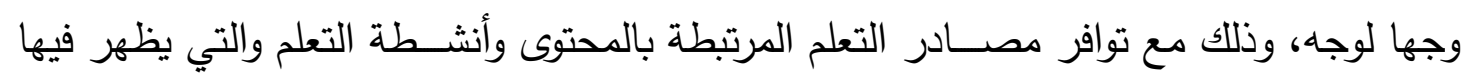
المزج بين التعليم عن بعد والتعليم التقليدي، فصـــيغة التعليم الهجين تأخذ بمبدأ التعليم المتمركز حول الطالب.

\section{الاتجاه نحو التعليم الهجين:}

مقدار أو شدة الانفعال التي يبديها أفراد العينة نحو التعليم الهجين بالرفض أو القبول أو الحيادية،

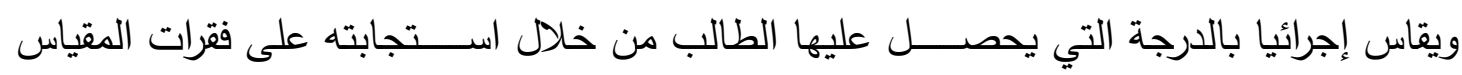

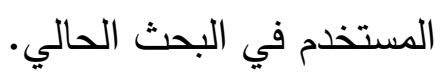


أجرى (جبرين عطية، وخليل عزمي، وخالد يوسف، 1 . . ب) دراسـة هدفت للكثف عن اتجاهات

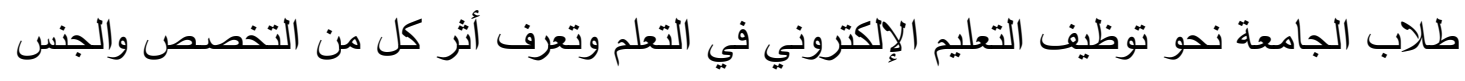
والخبرة في الإنترنت على تلك الاتجاهات، وأظهرت النتائج وجود اتجاهات إيجابية لإنى الطنلاب

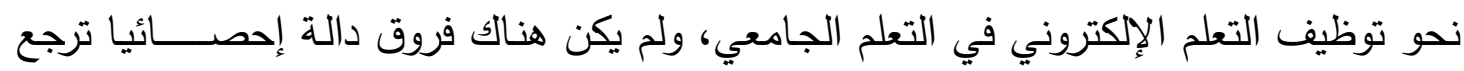

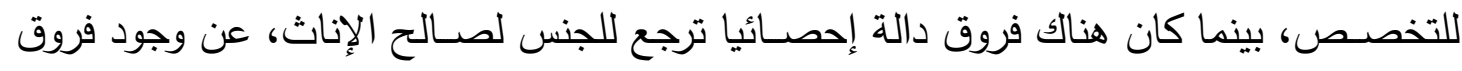

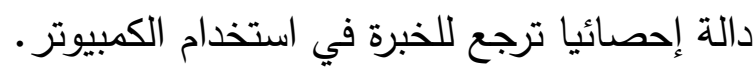
وفي بحث (Welcker \& Beradino, 2006) للتعرف على اتجاهـات الطلاب نحو التعليم

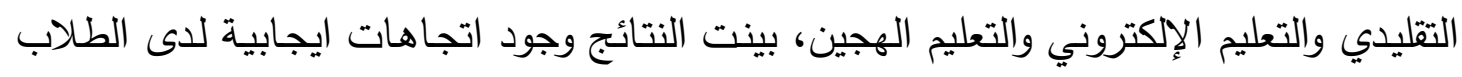

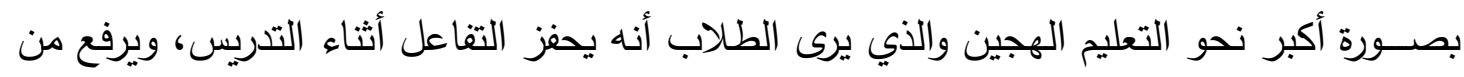

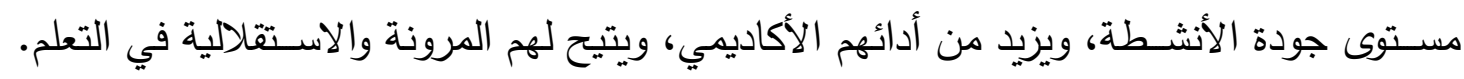

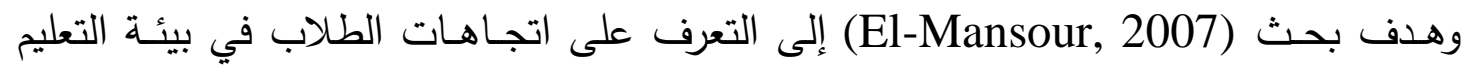

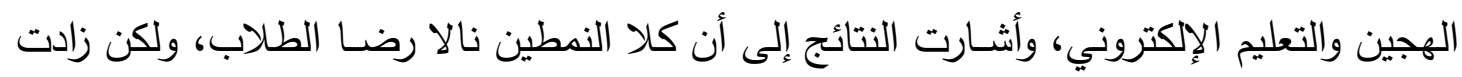

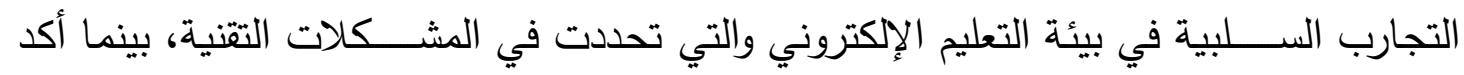

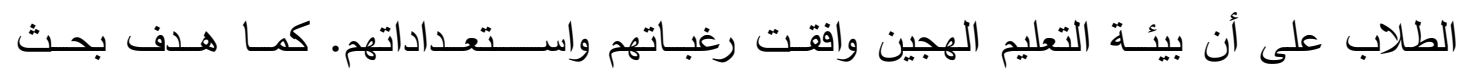

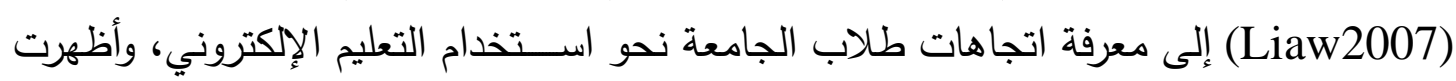

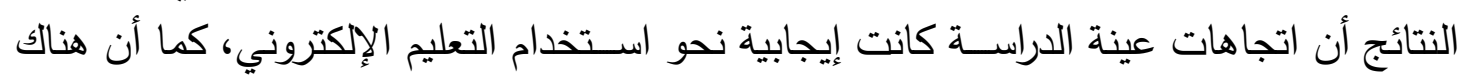
عوامل أخرى مؤثرة في اتجاهات الطلاب نحو التعليم الإكتروني تتعلق بالموقف التهابت التعليمي والتعلم

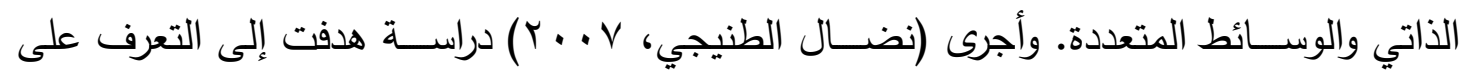

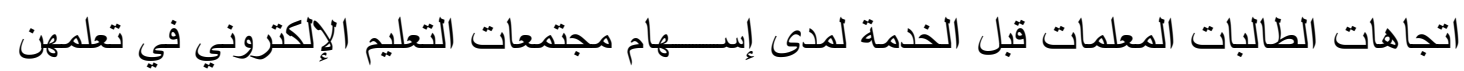

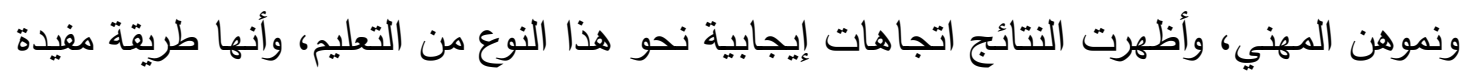

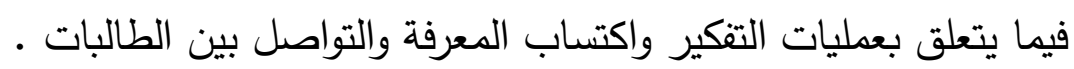

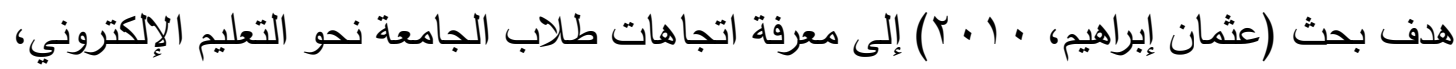

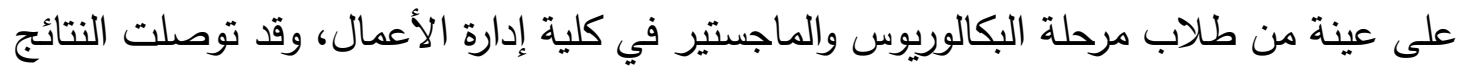

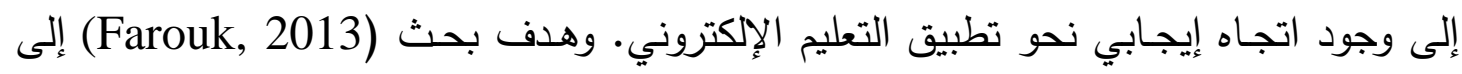

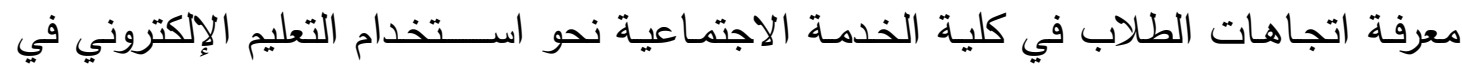

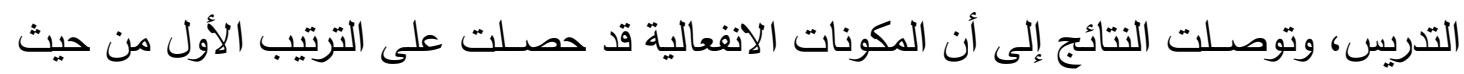
الأهمية يليها المكونات المعرفية ثم المكونات المهارية.

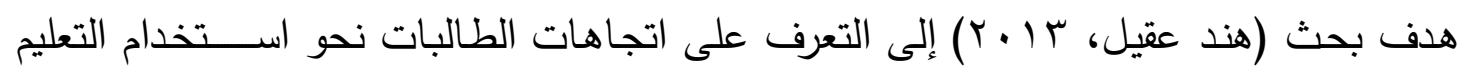

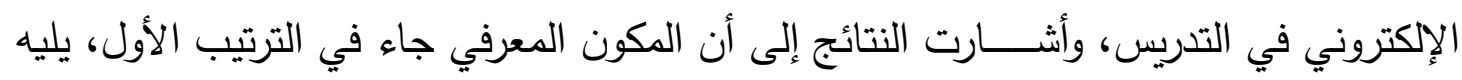

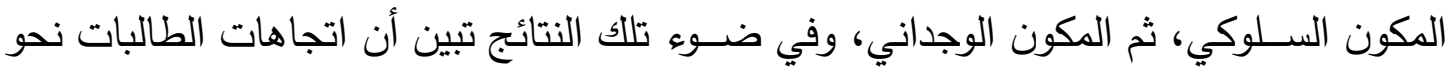

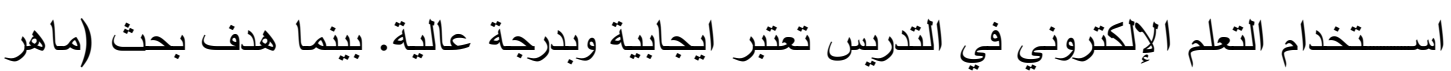




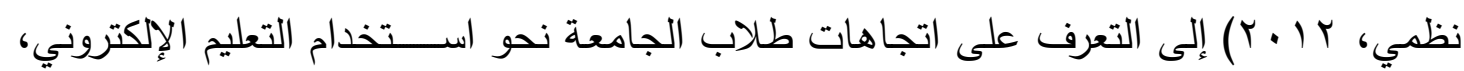

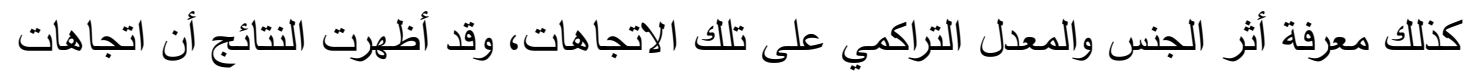

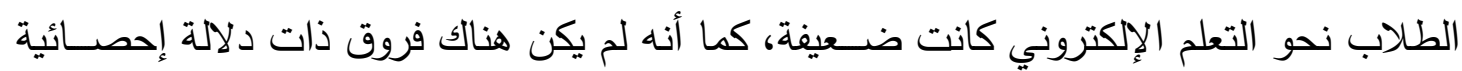
تعزي لمتغيري الجنس والمعدل التراكمي.

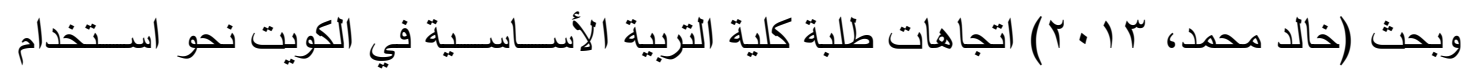

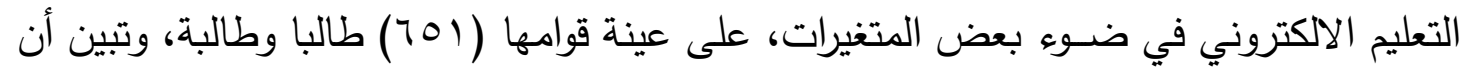

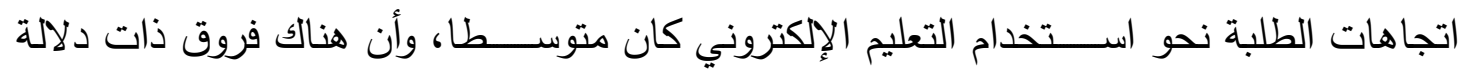

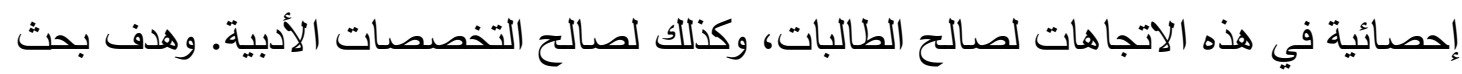

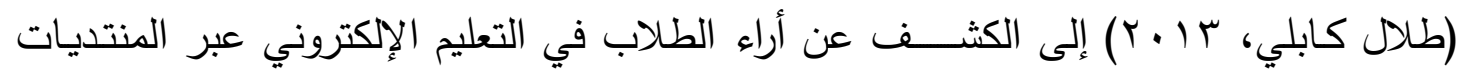

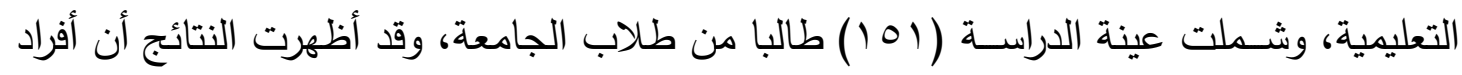
عينة الدراسة يوافقون بشدة على التعليم عن بعد.

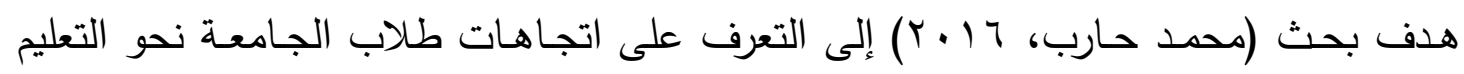

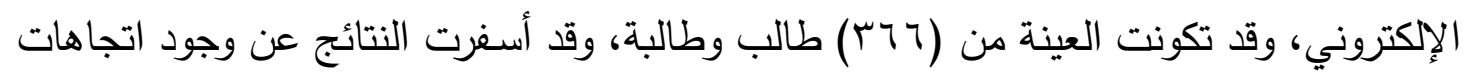

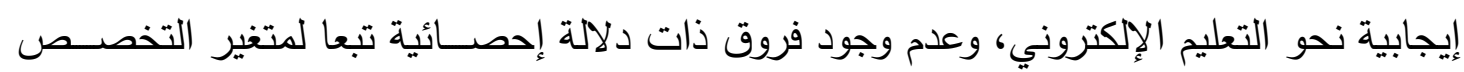

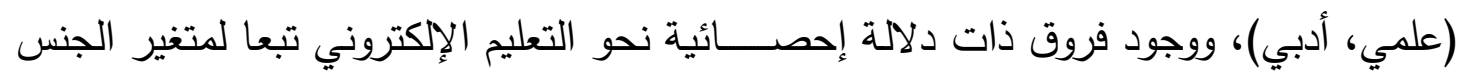

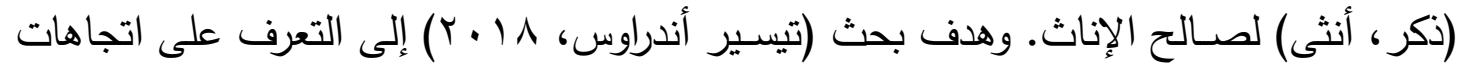

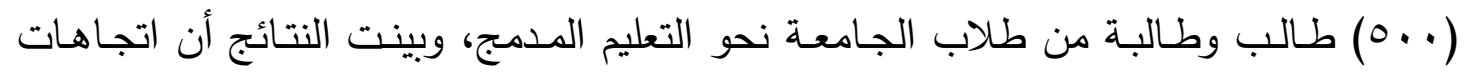

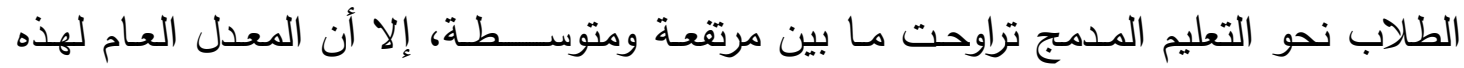

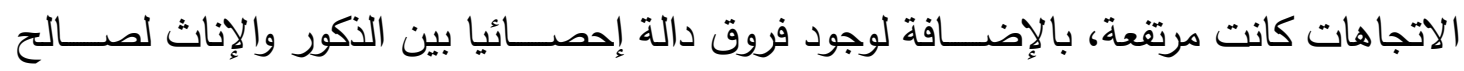

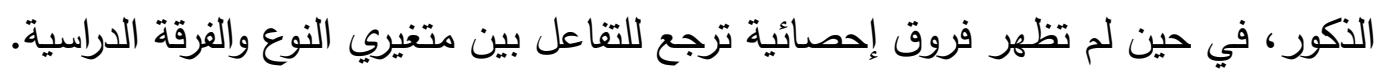

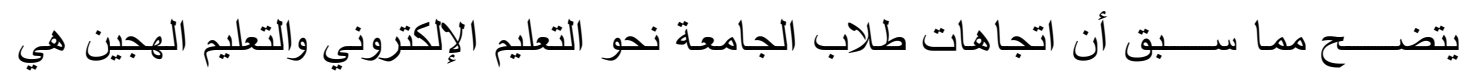

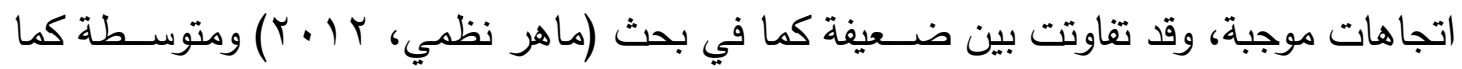

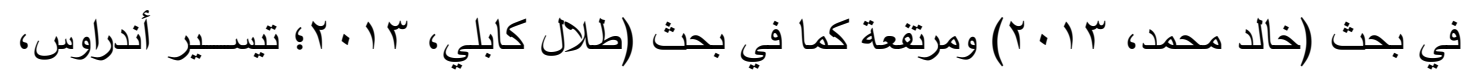

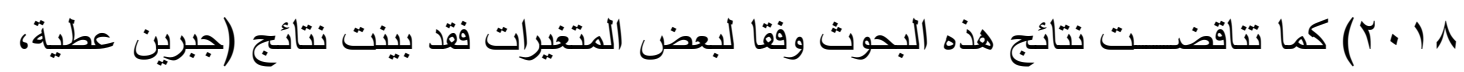

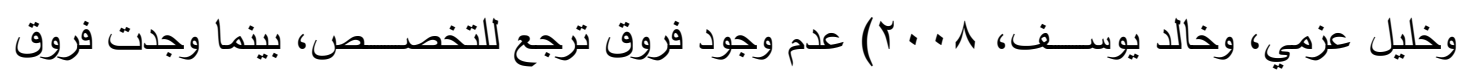

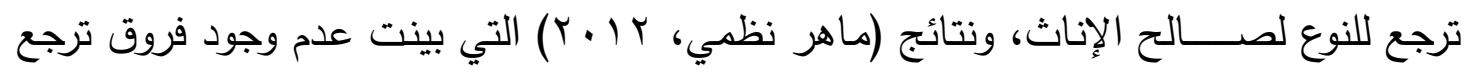

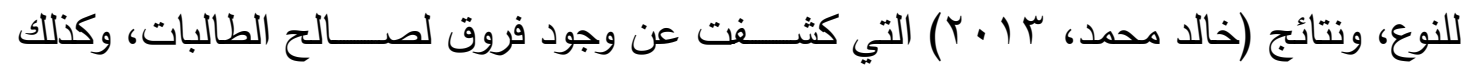

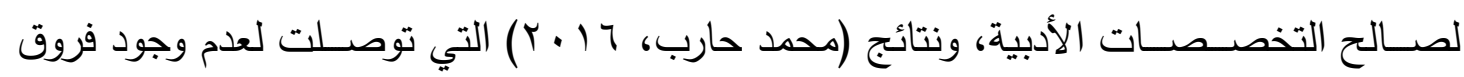

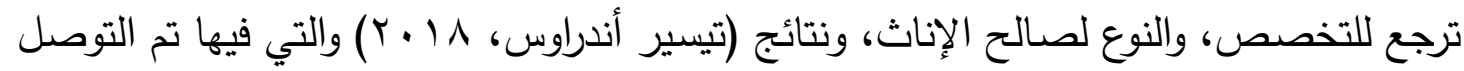

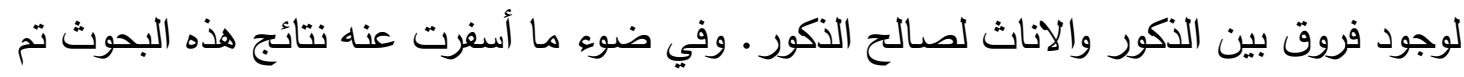

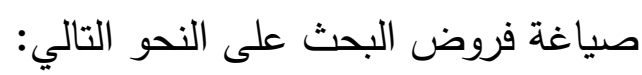




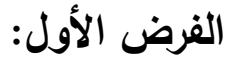

تتميز اتجاهات عينة البحث نحو التعليم عن بعد والتقليدي والهجين بأنها محايدة.

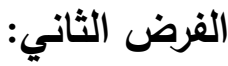

لا تختلف اتجـاهـات عينـة البحث نحو التعليم عن بعـد والتقليدي والهجين بـاختلاف: النوع والتخصص والفرق الدراسية.

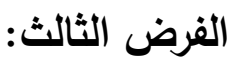
تفضل عينة البحث أنماط التعليم عن بعد والتقليدي والهجين بنسب متساوية.

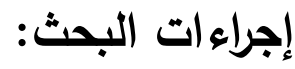

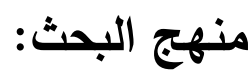
تم استخدام المنهج الوصفي؛ لملاءمته لطبيعة وأهداف البحث.

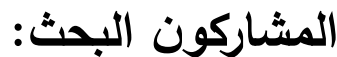

شارك في البحث (Y V Y ) طالب وطالبة من التخصصات العلمية والأدبية بالثعبة العامة وشعبة

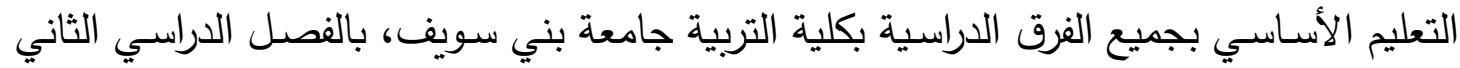

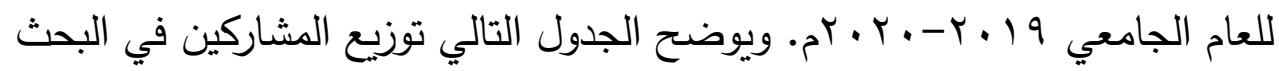

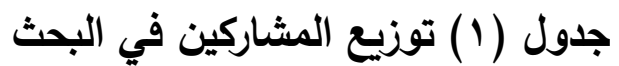

\begin{tabular}{|c|c|c|c|}
\hline النسبة المئوية & العدد & غيرات & \\
\hline$V Y . \wedge \varepsilon$ & 1507 & إناث & \multirow{2}{*}{ النوع } \\
\hline rY.17 & rᄉт & ذكور & \\
\hline r1.9V & $00 \mathrm{~V}$ & الفرقة الأولى & \multirow{4}{*}{ الفرقة } \\
\hline rT.lA & ov^ & الفرقة الثانية & \\
\hline 19.14 & TrT & الفرقة الثالثة & \\
\hline $10 . \mathrm{V} \pi$ & $r V \varepsilon$ & الفرقة الرابعة & \\
\hline$\varepsilon r . \leqslant 7$ & rov & التخصصات العلمية & \multirow{2}{*}{ التخصد } \\
\hline $07.0 \leqslant$ & 910 & التخصصات الأدبية & \\
\hline
\end{tabular}

أداة البحث: مقياس الاتجاه نحو التعليم عن بعد والتقليدي والهجين: اعداد الباحثة

ملحق (Y)

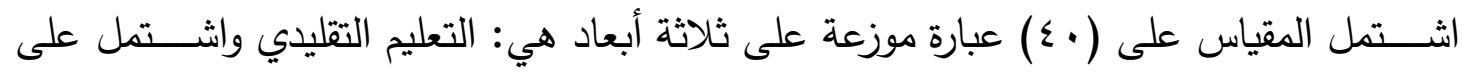

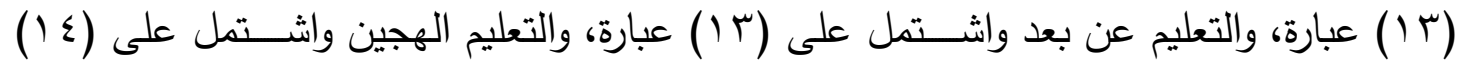

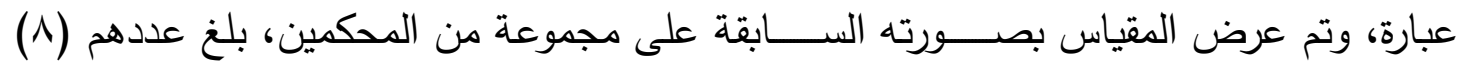

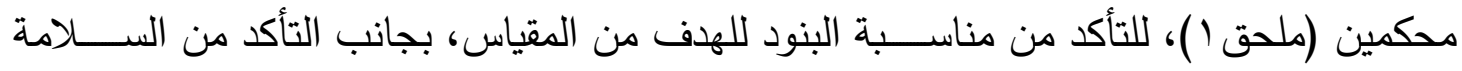
اللغوية لها، وتم عمل التعديلات التي أثـار بها المحكمون، ليصل علد عدد عبارات المقياس في هذه 
المرحلة إلى (ד؟T) عبارة موزعة على الأبعاد الثلاثة بالتشــــاوي، ثم تطبيق المقياس على العينة

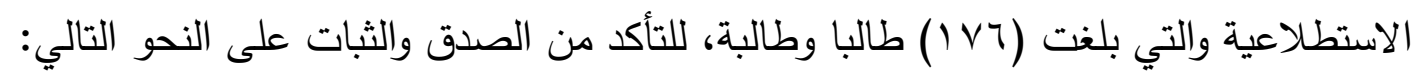

صدق المقياس:

تم اســـتخدام صـــدق المحك حيث بلغت قيمة معامل الارتباط بين الدرجة الكلية لعينة البحث

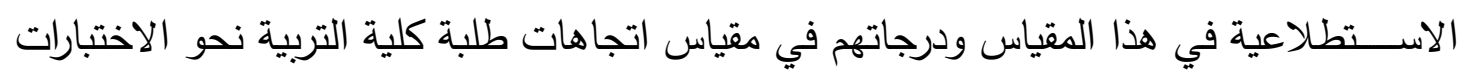

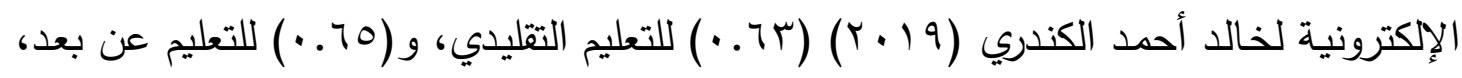

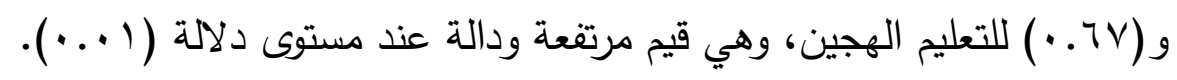
ثبات المقياس:

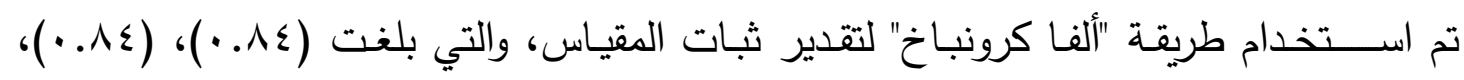

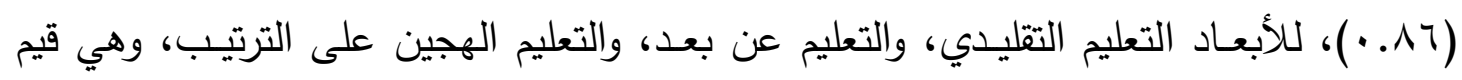
مرتفعة ويمكن الاعتماد عليها.

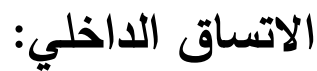
تراوحت قيم معاملات الارتباط بين درجات المقاييس الفرعية والدرجة الكلية للمقياس بين (بآ . )

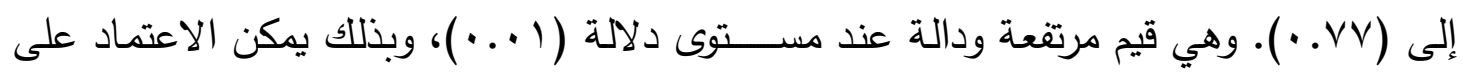

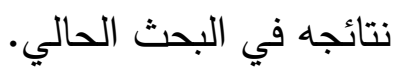

الاساليب الإحصائية المستخدمة: تم الاعتماد على المتوســطات الحســابية والتكرارات والنســـب المئوية، وتحليل التباين المتعدد، الإسها واختبار شـيفيه، وكا` باســتخدام برنامج (22) SPSS معالجة بيانات البحث الحالي والتحقق من الفروض. حدود البحث: تتحدد نتائج البحث الحالي بالعينة والأدوات والأساليب المستخدمة في معالجة البيانات. نتائج البحث: لاختبار صـحة الفرض الأول والذي ينص على: تتميز اتجاهات عينة البحث الحالي نحو

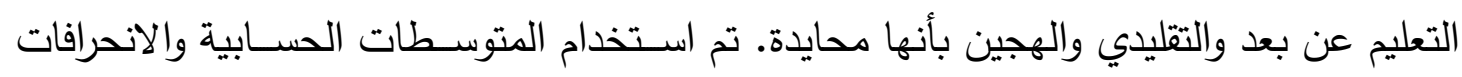

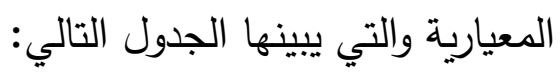

جدول (ץ)

المتوسطات والانحرافات المعيارية للمشاركين في البحث على مقياس البحث 


\begin{tabular}{|c|c|c|c|c|c|}
\hline التفرطح & معامل & النسبة المئوية & الانحراف & المتوبط & نمط التعليم \\
\hline .91 . & $.7 \vee \wedge$ & VV.TYE & ר.人Tr & $\leqslant 7.01$. & التعليم التقليدي \\
\hline .100 &.$\vee \vee 97$ & 77.189 & $1 \cdot .1$ & rq.v.v & التعليم عن بعد \\
\hline .991 &.$v 9 r$ & $V \leq . r .0$ & $1.9 \cdot 7$ & $\varepsilon \Sigma .0 \wedge \mu$ & التعليم الهجين \\
\hline
\end{tabular}

يتضـح من الجدول السـابق حيادية اتجاهات المشـاركين في البحث، حيث بلغ متوسـ اتجاهاتهم

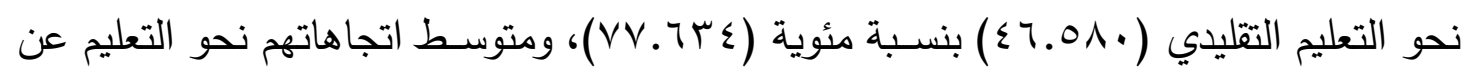

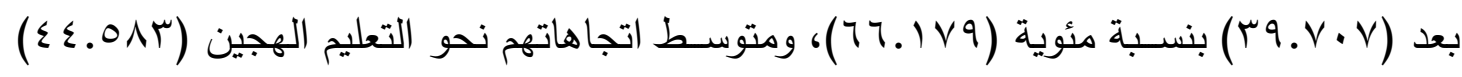
بنسبة مئوية (0 . . . V乏)، حيث تم حساب النسبة المئوية للمتوسط من خلال قسمة قيمة المتوسط على النهاية العظمى لنمط التعليم، كما كان توزيع بيانات المشــــاركين في البحث اعتداليا حيث

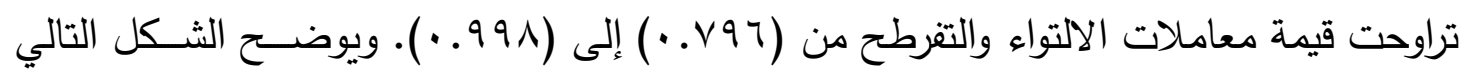
ذلك.

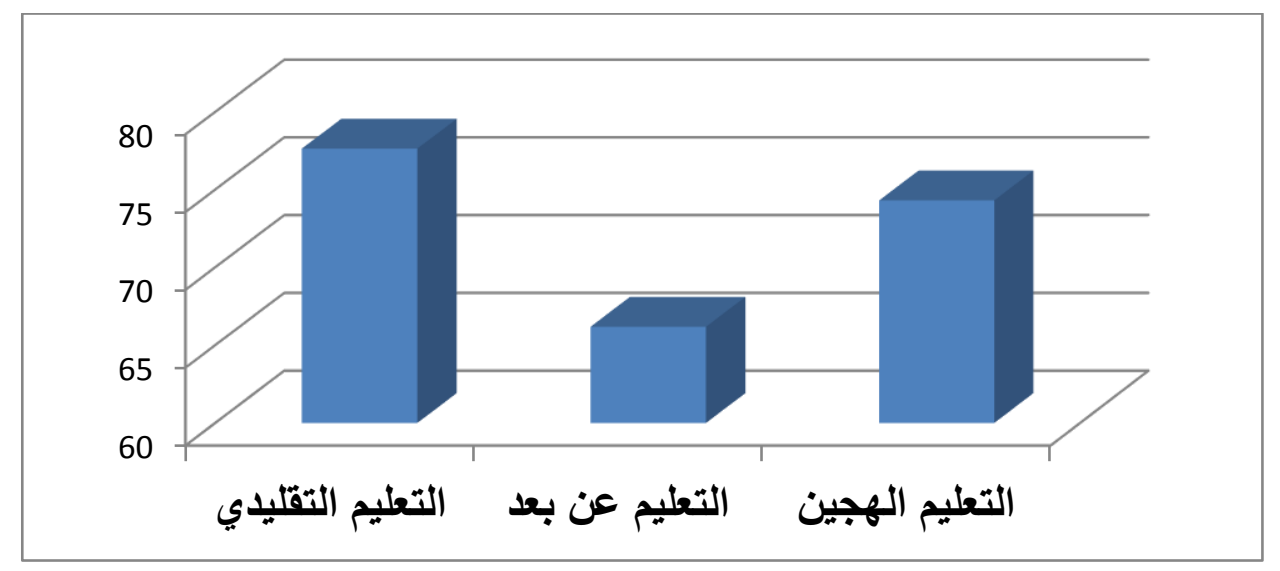

شكل (1)

النسب المئوية لمتوسط استجابات المشاركين في البحث لاتجاهاتهم نحو التعليم التقليدي

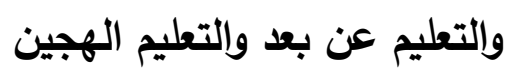

لاختبار صـحة الفرض الثاني والذي ينص على: لا تختلف اتجاهات عينة البحث الحالي

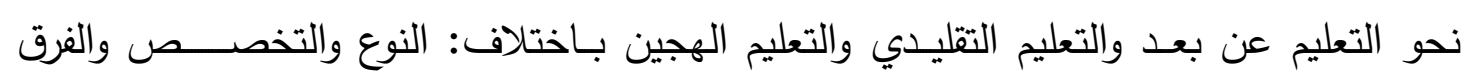

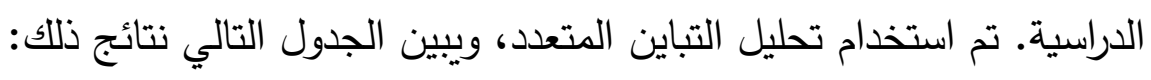

جدول (r) (r) 
نتائج تحليل التباين المتعدد لدلالة الفروق في اختلاف اتجاهات عينة البحث نحو التعليم عن بعد والتقليدي والهجين باختلاف النوع والتخصص والفرق الدراسية

\begin{tabular}{|c|c|c|c|c|c|c|}
\hline الدلالة & قيمة ف & متوســطات & الحرية & مجموع المربعات & نمط التعليم & المتغيرات \\
\hline .711 &. .179 & $\vee . \vee 9 \wedge$ & 1 & $\vee . \vee 9 \wedge$ & التعليم التقليدي & \multirow{3}{*}{ النوع } \\
\hline . . & $\ldots$ or & 0.117 & 1 & 0.117 & بعد التعليم عن & \\
\hline.$\leqslant \leqslant \leqslant 0$ &. $.01 r$ & $\varepsilon 0.9 \vee 9$ & 1 & $\varepsilon 0 . V 9 V$ & التعليم الخليط & \\
\hline$\cdots \cdots$ & K. & $0 \vee r .799$ & r & $\mid V Y 1.91$ & التعليم التقليدي & \multirow{3}{*}{ الفرقة } \\
\hline$\cdots \cdots$ & $0 . \vee \wedge \varepsilon$ & ONT.ETr & r & IVO..TNV & بعد التعليم عن & \\
\hline$\ldots r$ & $\varepsilon .011$ & rד. & r & l.sr.v.r & التعليم الخليط & \\
\hline.$\times 11$ &. $.1 r \mu$ & סד4. & 1 & סדיז.7 & التعليم التقليدي & \multirow{3}{*}{ التخصص } \\
\hline $.94 \cdot$ & $\ldots 1$ & $1 . . r$. & 1 & $1 . . r$. & بعد التعليم عن & \\
\hline $.1 \vee \leq \varepsilon$ & 1.101 & $1 \leqslant 0.9 r q$ & 1 & $1 \leq 0.949$ & التعليم الخليط & \\
\hline & & $\{7 . Y 17$ & IVTr & $\Lambda . r r \cdot . T r \Lambda$ & التعليم التقليدي & \multirow{3}{*}{ الخطأ } \\
\hline & & $1 \ldots \wedge V r$ & IVTr & $|v 01| \leq .011$ & بعد التعليم عن & \\
\hline & & $\vee \wedge . \wedge \leqslant 7$ & צמיד & 1 1 TAv9.19r & التعليم الخليط & \\
\hline
\end{tabular}

\section{يتضح من الجدول السابق ما يلي:}

لا تختلف اتجاهات عينة البحث نحو التعليم عن بعد والتعليم التقليدي والتعليم الهجين باختلاف النوع (ذكر انثى)، ويوضـح الجدول والثكل التالي المتوسطات للذكور والإناث

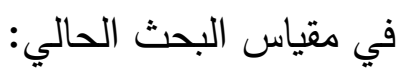


جدول ( ) متوسطات الذكور والإناث في مقياس البحث

\begin{tabular}{|c|c|c|}
\hline المتوسط & النوع & نمط التعليم \\
\hline 纟ั. rฯV & إناث & \multirow{2}{*}{ التعليم التقليدي } \\
\hline$\varepsilon T . Y \cdot \varepsilon$ & ذكور & \\
\hline 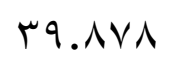 & إناث & \multirow{2}{*}{ التعليم عن بعد } \\
\hline rq.vrq & ذكور & \\
\hline$\varepsilon \varepsilon .9 \cdot 1$ & إناث & \multirow{2}{*}{ التعليم الهجين } \\
\hline$\varepsilon \varepsilon .01 \pi$ & ذكور & \\
\hline
\end{tabular}

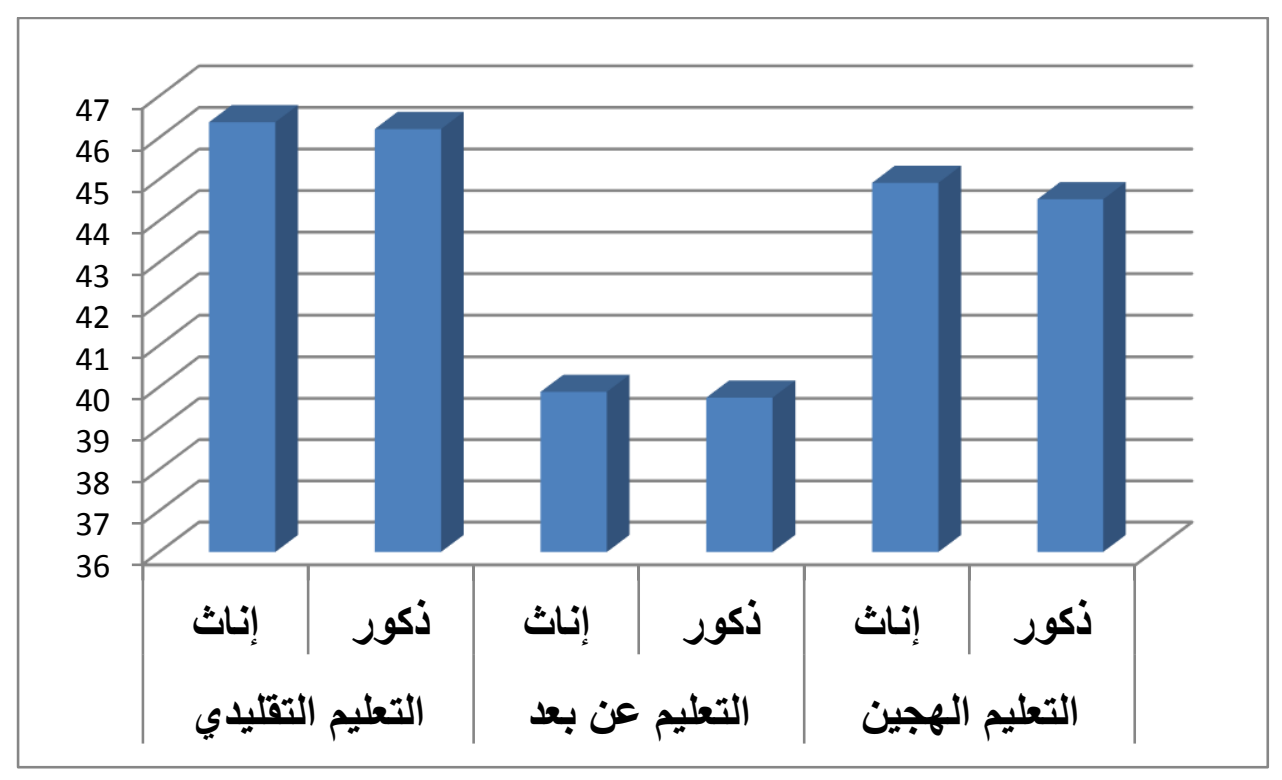

شكل (r)

متوسطات الذكور والإناث في مقياس البحث

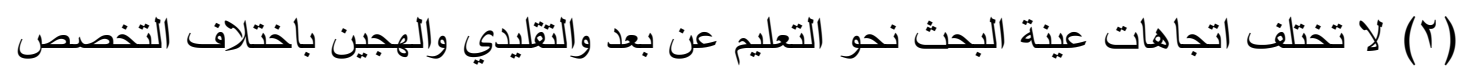

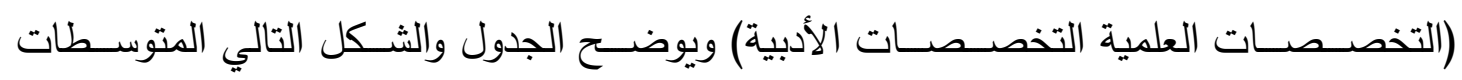
للتخصصات العلمية والأدبية في مقياس البحث الحالي: 
جدول (0) متوسطات التخصصات العلمية والأدبية في مقياس البحث

\begin{tabular}{|c|c|c|}
\hline المتوسط & التخصص & نمط التعليم \\
\hline$\leqslant 7 . r \leqslant V$ & التخصصات العلمية & \multirow{2}{*}{ التعليم التقليدي } \\
\hline$\Sigma T . Y T \leqslant$ & التخصصات الأدبية & \\
\hline 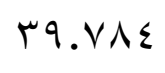 & التخصصات العلمية & \multirow{2}{*}{ التعليم عن بعد } \\
\hline rq.人r & التخصصات الأدبية & \\
\hline$\leqslant 0 \ldots 1$ & التخصصات العلمية & \multirow{2}{*}{ التعليم الهجين } \\
\hline$\leqslant \leqslant . \leqslant 10$ & التخصصات الأدبية & \\
\hline
\end{tabular}

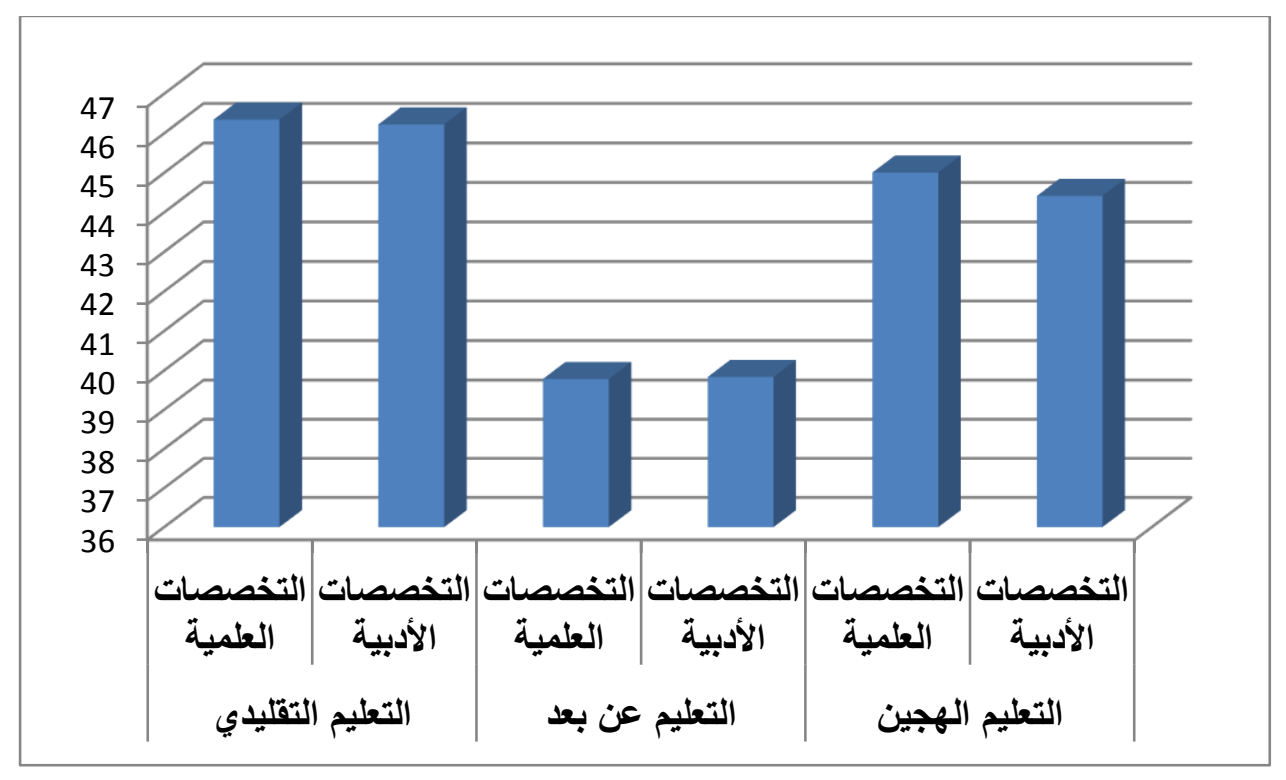

شكل (r)

متوسطات التخصصات العلمية والأدبية في مقياس البحث

(r) تختلف اتجاهات عينة البحث الحالي نحو التعليم عن بعد والتعليم التقليدي والتعليم الهجين باختلاف الفرقة الدراسـية وللتعرف على دلالة تلك الفروق تم اسـتخدام اختبار شـيفيه والذي يبين نتائجه جدول (†) التالي. 
جدول (†) نتائج اختبار شيفيه لالالة الفروق بين الفرق الدراسية في مقياس الاتجاهات

\begin{tabular}{|c|c|c|c|}
\hline المتوسط & الفرقة الاراسية & الفرقة الدراسية & نمط التعليم \\
\hline *1. sor & الفرقة الثانية & الفرقة الأولى & \multirow{6}{*}{ لتعليم التقليدي } \\
\hline$* 1.110$ & الفرقة الثالثة & & \\
\hline$* Y .9 \leqslant 1$ & الفرقة الرابعة & & \\
\hline תוד. & الفرقة الثالثة & الفرقة الثانية & \\
\hline *1.1Y7 & الفرقة الرابعة & & \\
\hline *1.1K4 & الفرقة الرابعة & الفرقة الثالثة & \\
\hline *1. vor & الفرقة الثانية & الفرقة الأولى & \multirow{6}{*}{ التعليم عن بعد } \\
\hline$* 1 . \varepsilon .0$ & الفرقة الثالثة & & \\
\hline .91 & الفرقة الرابعة & & \\
\hline 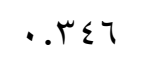 & الفرقة الثالثة & الفرقة الثانية & \\
\hline *ห.TーT & الفرقة الرابعة & & \\
\hline *Y.TIO & الفرقة الرابعة & الفرقة الثالثة & \\
\hline..$\vee 99$ & الفرقة الثانية & الفرقة الأولى & \multirow{6}{*}{ التعليم الهجين } \\
\hline . TOY & الفرقة الثالثة & & \\
\hline *1.or. & الفرقة الرابعة & & \\
\hline..$\leqslant \leqslant V$ & الفرقة الثالثة & الفرقة الثانية & \\
\hline *1. AVr & الفرقة الرابعة & & \\
\hline *1.AVY & الفرقة الرابعة & الفرقة الثالثة & \\
\hline
\end{tabular}

* دالة عند 0... يتضح من الجدول السابق ما يلي:

أولا: بالنسبة للتعليم التقليدي: وجود فروق دالة إحصائيا بين الفرقة الأولى وكل من: الفرقة الثانية والفرقة الثالثة والفرقة الرابعة لصــالح الفرقة الأولى، وعدم وجود فروق دالة إحصــائيا بين الفرقة الثانية والفرقة الثالثة، ووجود فروق دالة إحصـائيا بين الفرقة الثانية والفرقة الرابعة لصـالح الفرقة الثانية، ووجود فروق دالة إحصـائيا بين الفرقة الثالثة والفرقة الرابعة لصـالح الفرقة الثالثة. كما يوضح ذللك الجدول والثكل التالي. ثانيا: بالنسـبة للتعليم عن بعد: وجود فروق دالة إحصـائيا بين الفرقة الأولى وكل من الفرقة الثانية والفرقة الثالثة لصــالح الفرقة الأولى، وعدم وجود فروق دالة إحصـــائيا بين الفرقة الأولى الثى والفرقة الرابعة، وعدم وجود فروق دالة إحصــــائيا بين الفرقة الثانية والفرقة الثالثة، ووجود فروق 
دالة إحصـائيا بين الفرقة الرابعة وكل من الفرقة الثانية والفرقة الثالثة لصـالح الفرقة الرابعة. كما يوضح ذلك الجدول والثكل التالي. ثالثا: بالنســبة للتعليم الهجين: عدم وجود فروق دالة إحصـائيا بين الفرقة الأولى وكل من

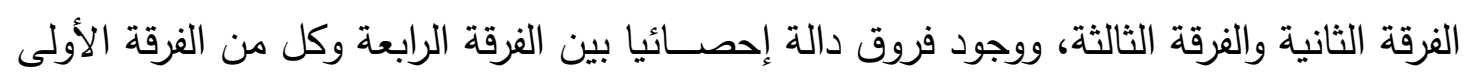

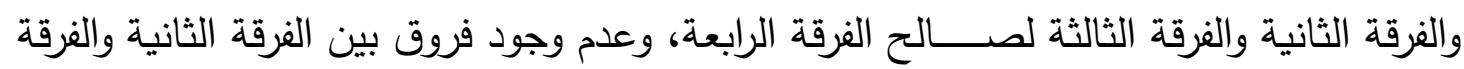
الثالثة. كما يوضح ذلك الجدول والثكل التالي.

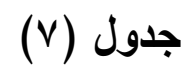

\begin{tabular}{|c|c|c|}
\hline \multicolumn{3}{|c|}{ متوسطات الفرق الدراسية في مقياس البحث } \\
\hline المتوسط & الفرق الدراسية & نمط التعليم \\
\hline$\sum V . \wedge r T$ & الفرقة الأولى & \multirow{4}{*}{ التعليم التقليدي } \\
\hline$\leq ૫ . \Upsilon \wedge \uparrow$ & الفرقة الثانية & \\
\hline$\sum \tau . \cdot Y Y$ & 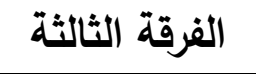 & \\
\hline$\varepsilon \varepsilon .91$. & الفرقة الرابعة & \\
\hline$\varepsilon . .479$ & الفرقة الأولى & \multirow{4}{*}{ التعليم عن بعد } \\
\hline rᄉ. & الفرقة الثانية & \\
\hline r $1.90 \mathrm{~V}$ & الفرقة الثالثة & \\
\hline$\sum 1$. YVT & الفرقة الرابعة & \\
\hline$\varepsilon \varepsilon .07 r$ & الفرقة الأولى & \multirow{4}{*}{ التعليم الهجين } \\
\hline$\leq r . \vee 9 \varepsilon$ & الفرقة الثانية & \\
\hline$\varepsilon \varepsilon . Y \wedge)$ & 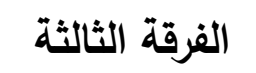 & \\
\hline$\leq T . Y .0$ & الفرقة الرابعة & \\
\hline
\end{tabular}




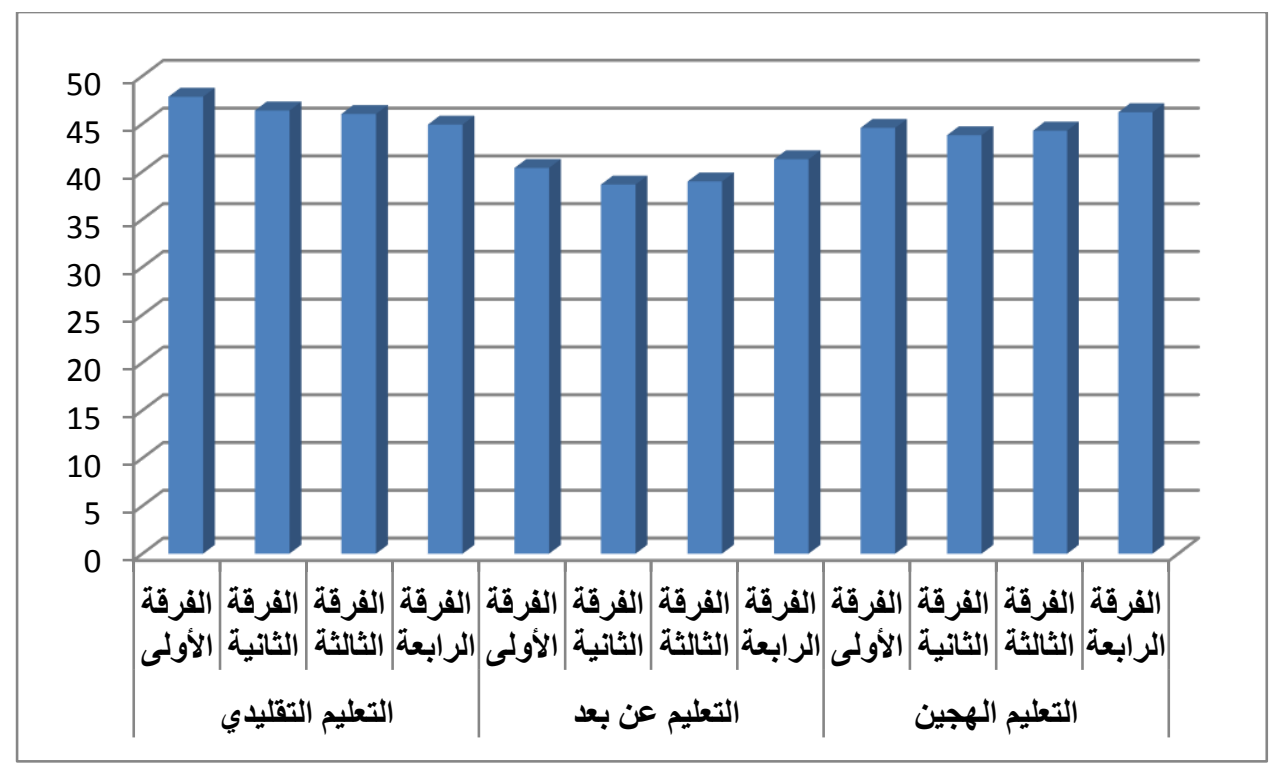

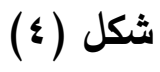

\section{متوبطات الفرق الاراسية في مقياس البحث}

لاختبار صــحة الفرض الثالث والأي ينص على: تفضـل عينة البحث الحالي أنماط التعليم عن بعد والتعليم التقليدي والتعليم الهجين بنسب متساوية. تم استخدام التكرارات والنسب المئوية وكا؟، ويوضح الجدول التالي نتائج ذك.

جدول (^)

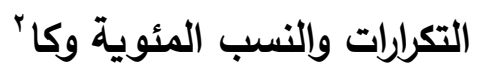

\begin{tabular}{|c|c|c|c|}
\hline كا' & النسبة المئوية & التكرار & نمط التعليم \\
\hline \multirow{3}{*}{$\varepsilon \wedge 1 . . \vee\urcorner$} & $\%$ & Avi & التعليم التقليدي \\
\hline & $\% .1 Y V$ & 109 & التعليم عن بعد \\
\hline & $\% \varepsilon \cdot . \wedge \vee r$ & VIr & التعليم الخليط \\
\hline
\end{tabular}

يتضح من الجدول السابق دلالة الفروق بين تكرارات تفضيل الطلاب لنمط التعليم فقد بلغت قيمة

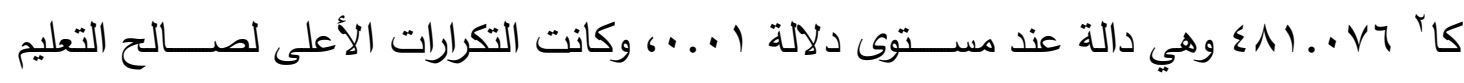

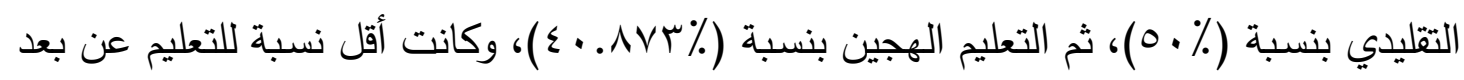
.$(\% ., Y V)$

\section{مناقشة وتفسير النتائج:}

بينت نتائج البحث الحالي وجود اتجاهات محايدة لدى طلاب الجامعة نحو التعليم التقليدي، والتعليم عن بعد، والتعليم الهجين، ووجود اتجاهات موجبة بصـــورة أفضـــل لاى طلاب الفرقة الأولى نحو التعليم التقليدي، بينما كانت اتجاهات طلاب الفرقة الرابعة نحو التعليم الهجين موجبة 
وبصورة أفضل، وعدم وجود فروق بين طلاب الفرقة الثانية والثالثة في أي من أنماط التعليم. كما

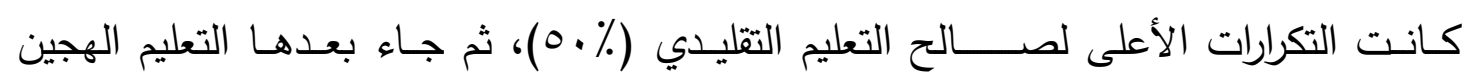

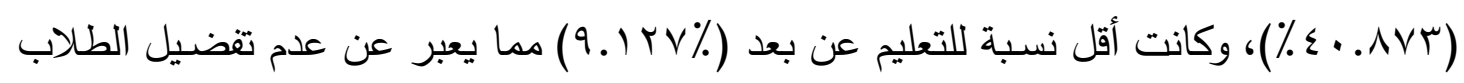

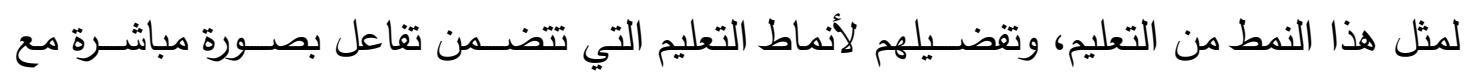

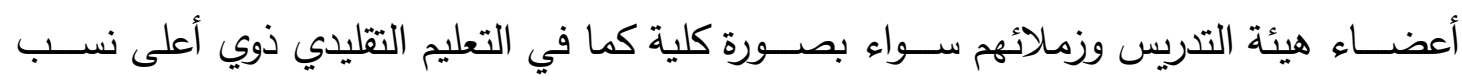

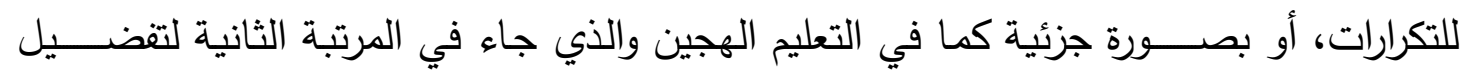
الطلاب.

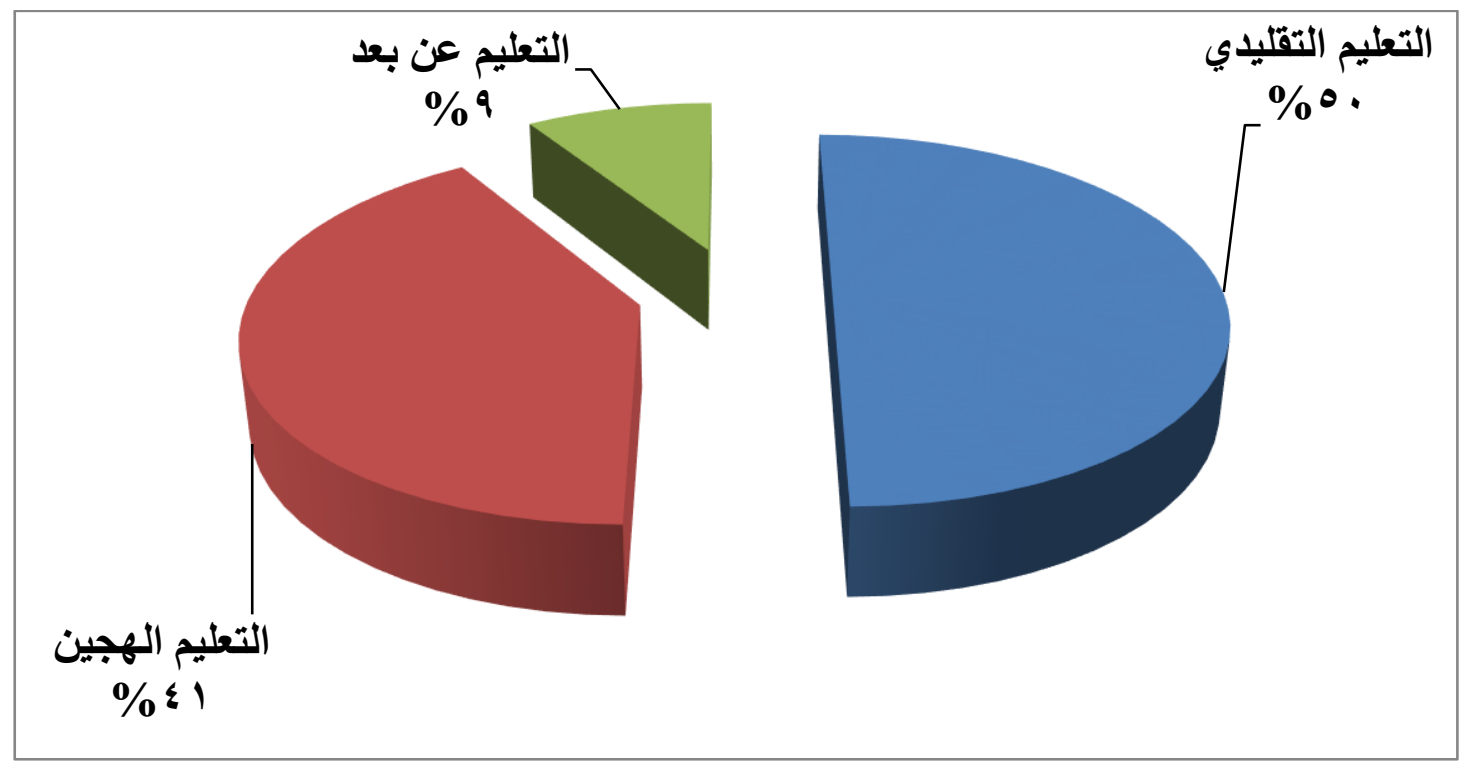

شكل (0)

\section{نسب تفضيل عينة البحث لأنماط التعليم المختلفة}

وتتفق هذه النتائج مع نتائج العديد من البحوث السـابقة والتي بينت أن اتجاهات طلاب الجامعة

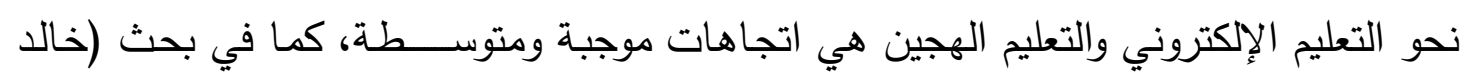

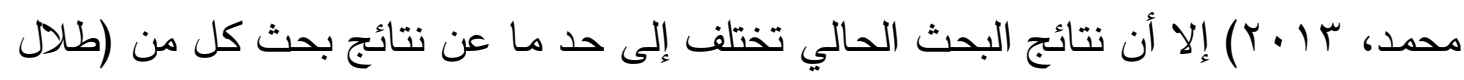

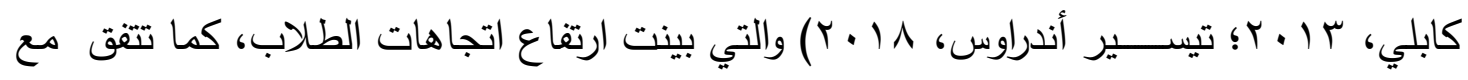

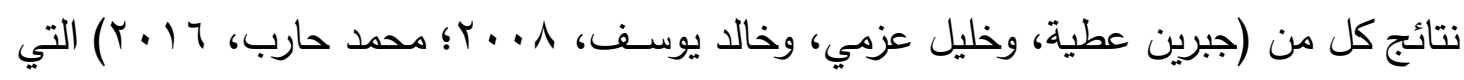

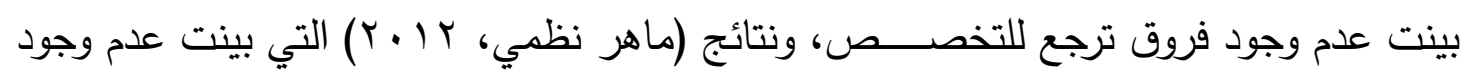
فروق ترجع للنوع، بينما تختلف نتائج البحث الحالي مع نتائج كل من (جبرين عطية، وخئ وخليل

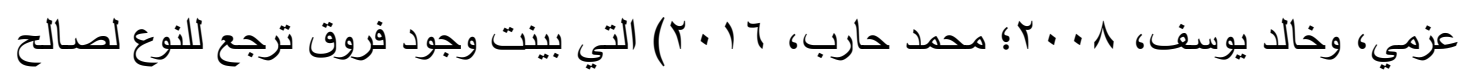

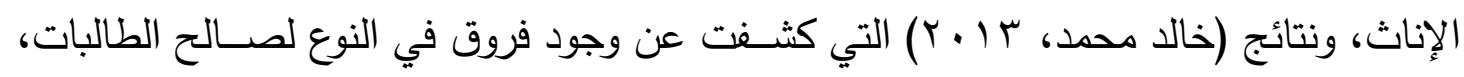




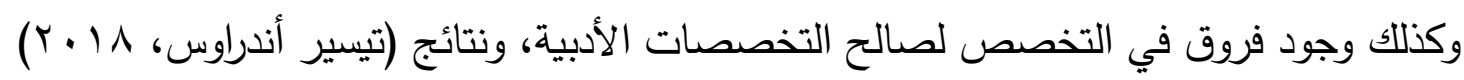
والتي فيها تم التوصل لوجود فروق بين الذكور والإناث لصالح الذكور .

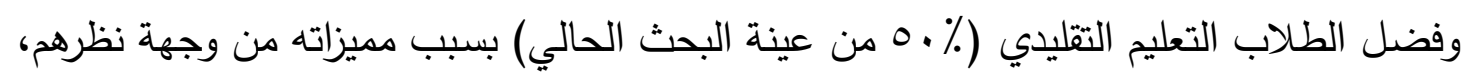

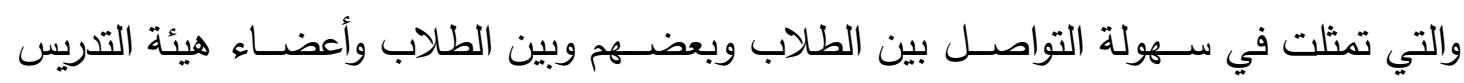

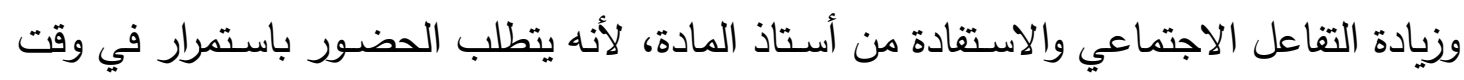

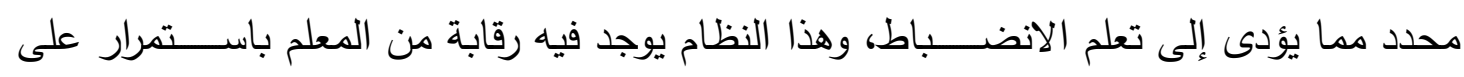

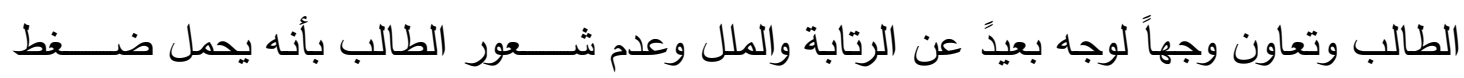

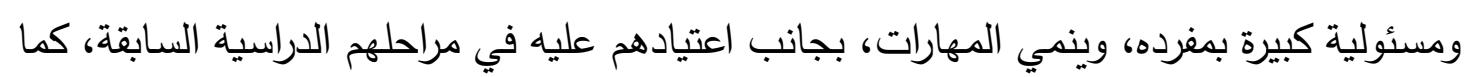

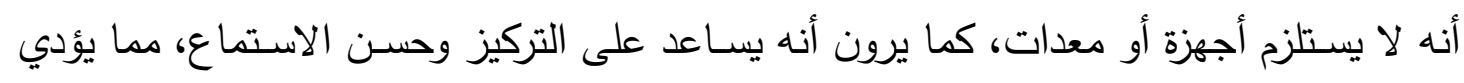

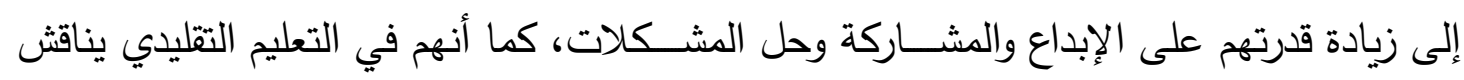

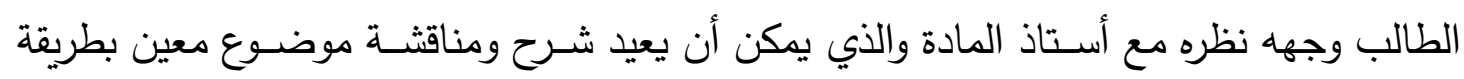
وبأســلوب آخر مما يســاعدهم على الفهم والمذاكرة من خلال التتافس بينه وبين زملائه فالتعليم

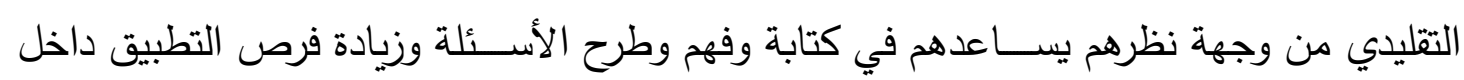

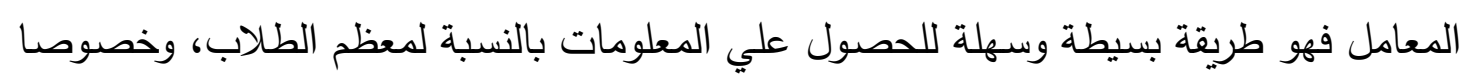

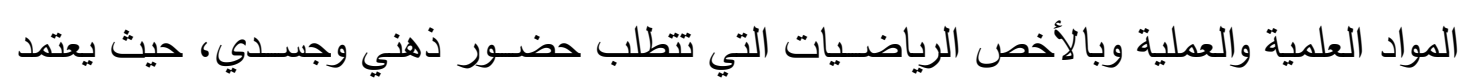
على العديد من الحواس كالسمع والبصر كما أنه متاح للجميع، ومستخدم في كافة البلدان، ويتيح فرص التعلم التعاوني، ويسمح لأستاذ المقرر القيام بعملية التربية بجانب التعليم من خلال إعطاء

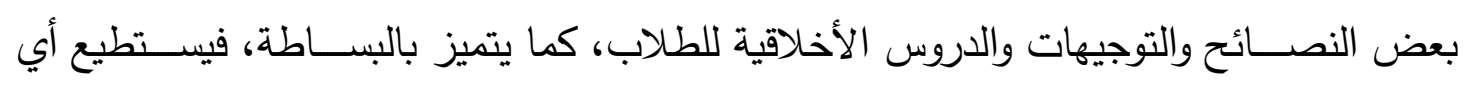
طالب دراســته بغض النظر عن حالته المادية، ويكون على الطالب اتباع قوانين النظام التقليدي لتئي التي تساعده في عدم إهدار الوقت.

ومن جانب آخر فإن التعليم عن بعد يحتاج إلى إمكانات مادية وتجهيزات إلكترونية وبنية تحتية

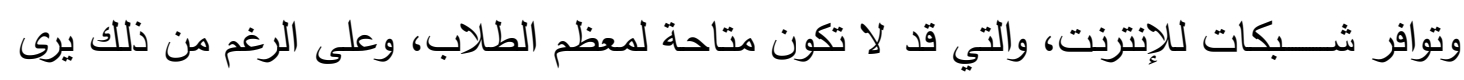

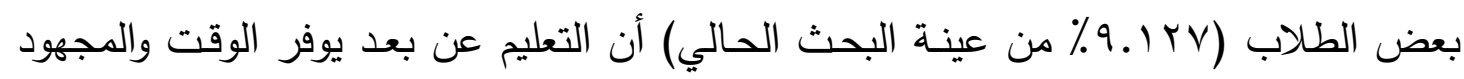

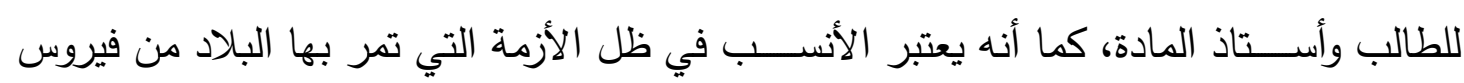

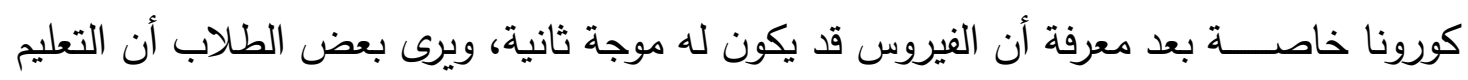

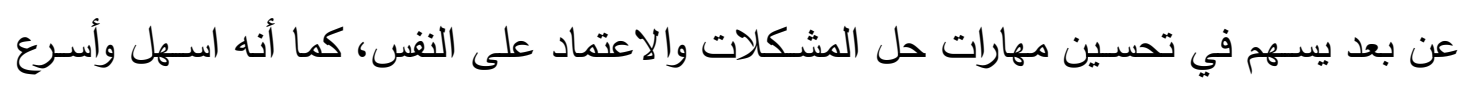

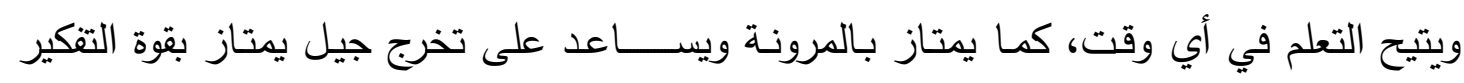

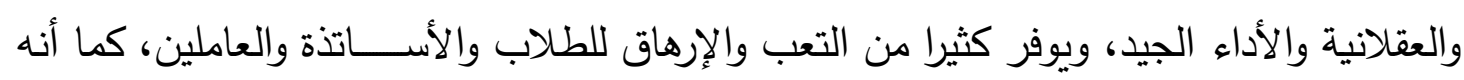

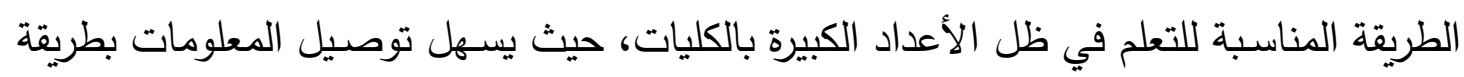

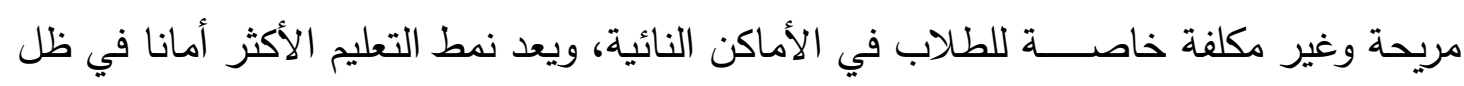


هذه الظروف، كما أنه يتيح إمكانية إعادة الثـــرح أكثر من مرة والتي قد لا تتوافر في التعليم

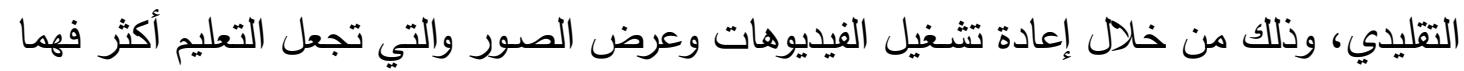

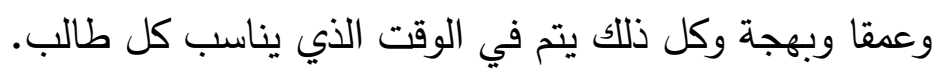

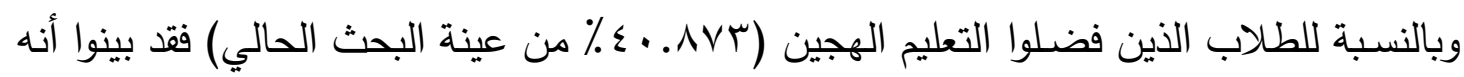

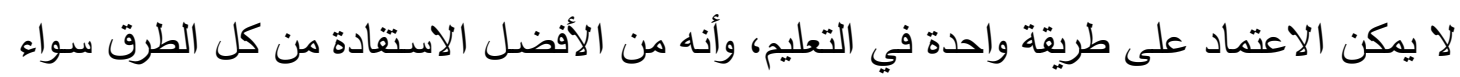

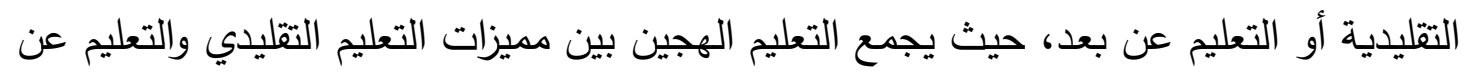

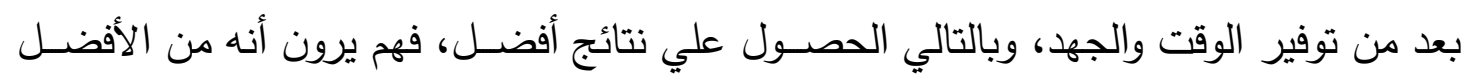

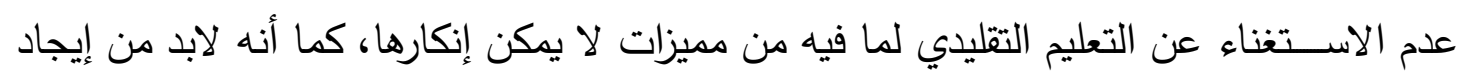

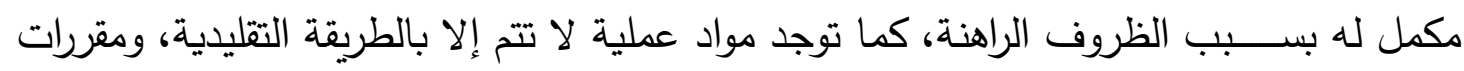

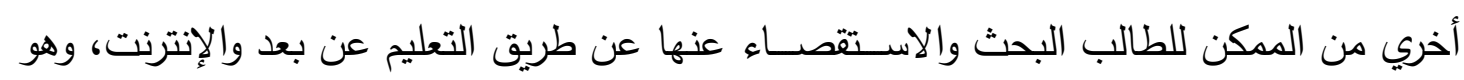

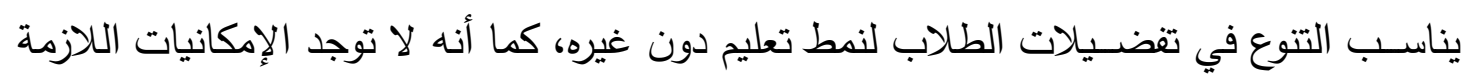

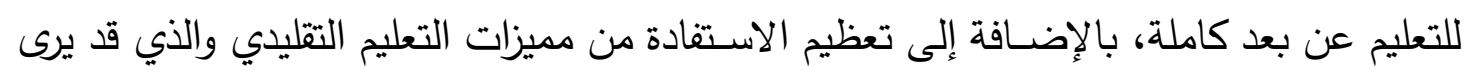

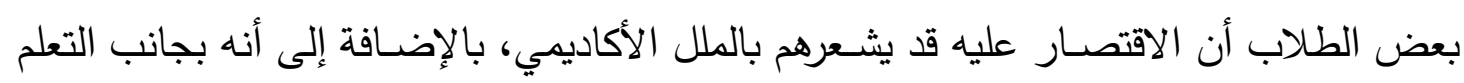

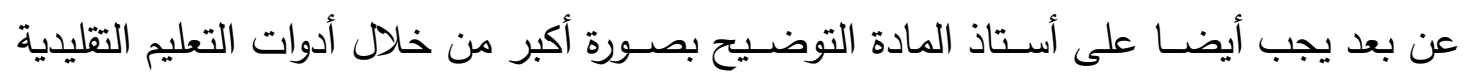

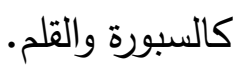

التوصيات:

عمل ورش عمل وندوات لتغيير اتجاهات الطلاب في تفضيلهم للتعليم التقليدي.

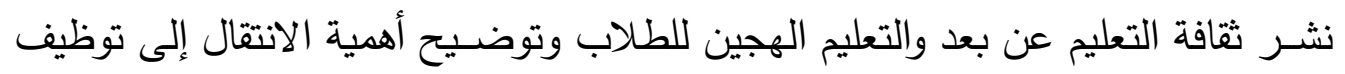

$$
\text { ه التكنولوجيا في مساعدتهم على التعلم. }
$$

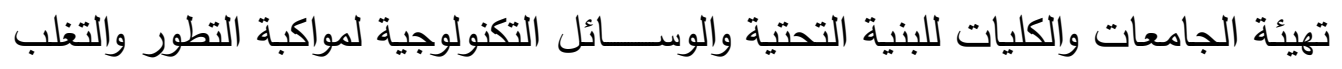

على بعد المكان واختلاف الزمان في التواصل مع الطلاب.

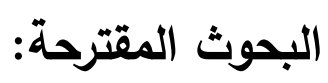

بحث معوقات تطبيق التعليم الهجين وطرق التغلب عليها. بحث العوامل النفسية المرتبطة بنجاح الطلاب في التعليم الهجين . هراسة أثر نوع الطلاب وتخصصهم على الأداء الأكاديمي في نمط التعليم الهجين. هراسة أثر التعليم الهجين على دافعية الطلاب.

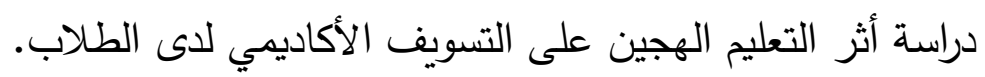




\section{المراجع}

أولا: المراجع العربية:

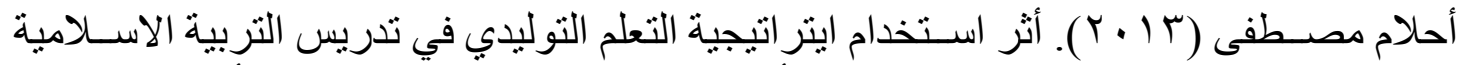

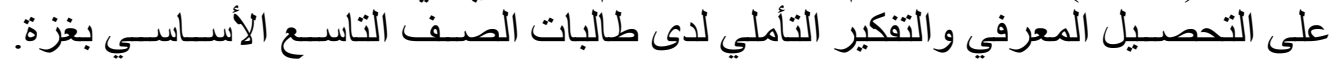

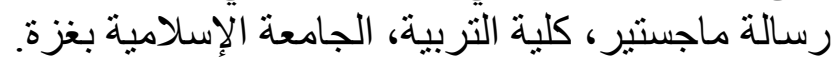

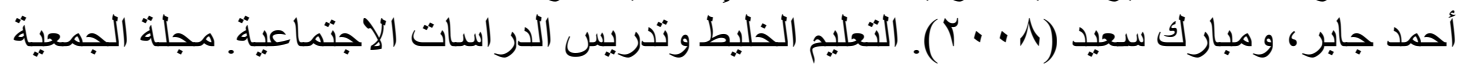

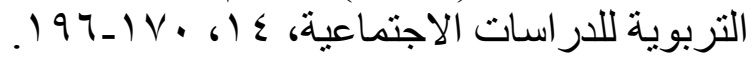

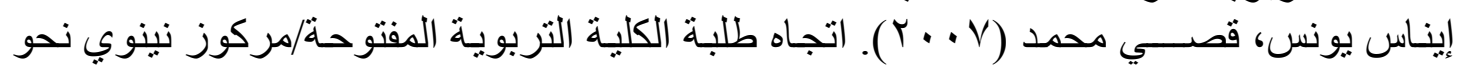

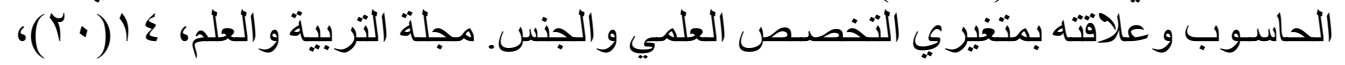

r

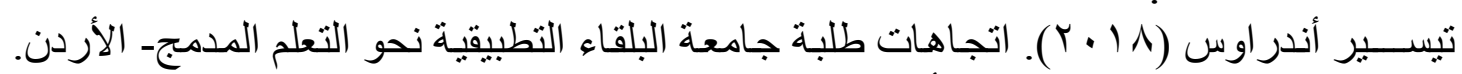

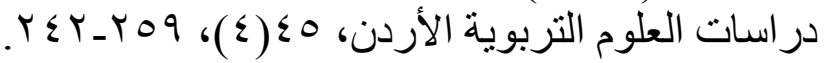

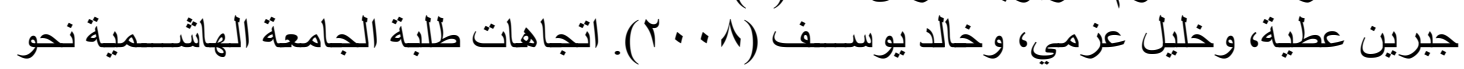

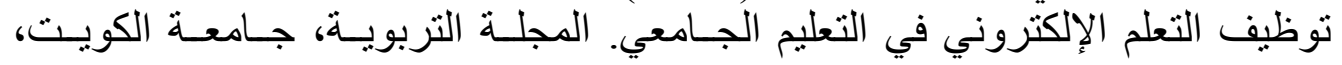

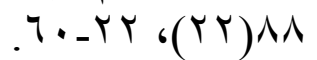

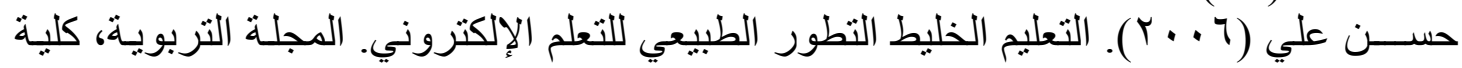

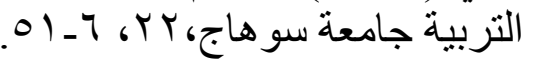

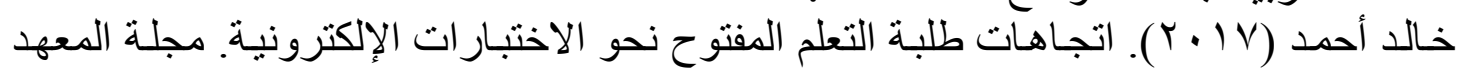

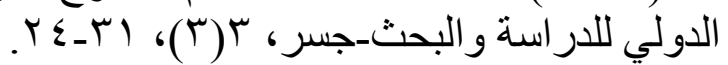

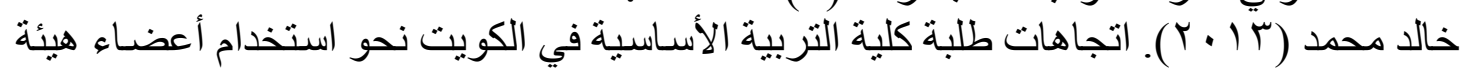

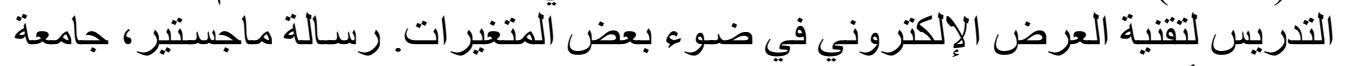
الشرق الأوسط.

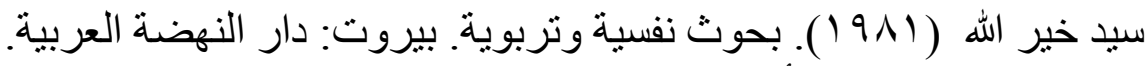

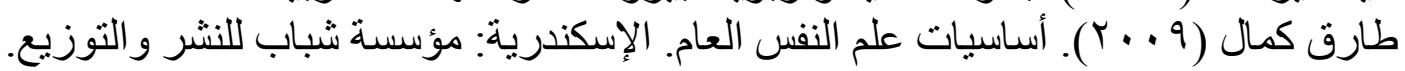

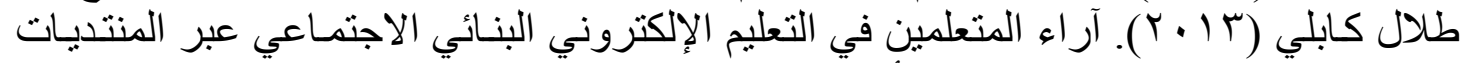

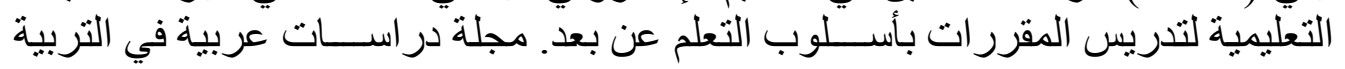

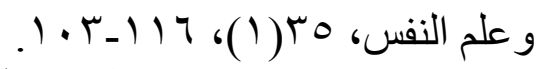

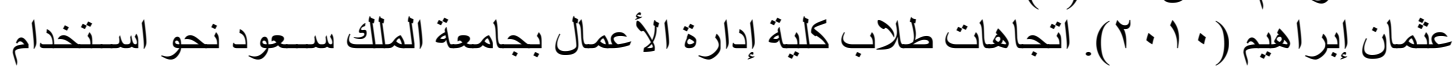

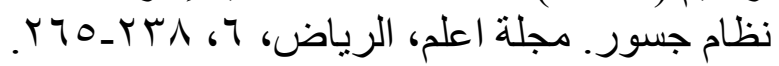

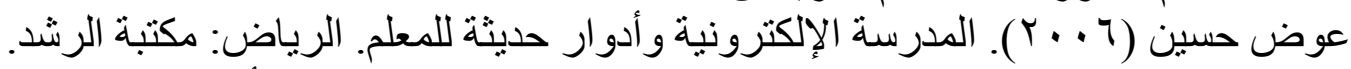

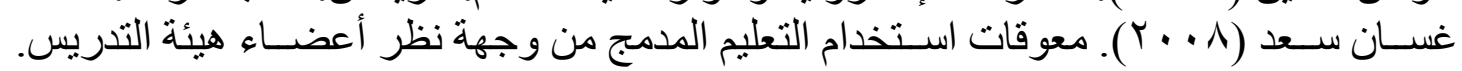

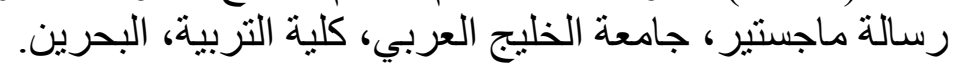

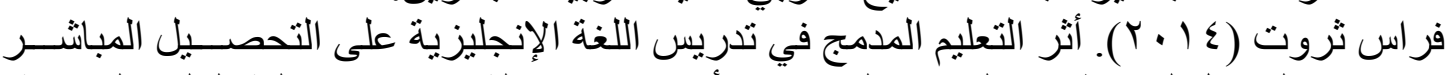

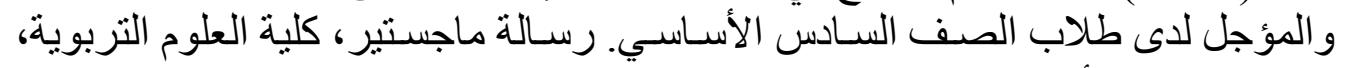
جامعة الثرق الأوسط.

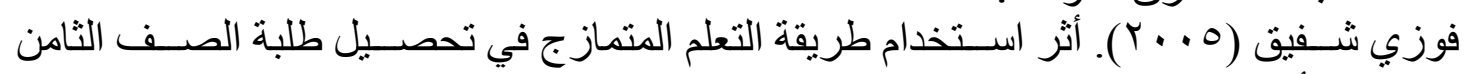

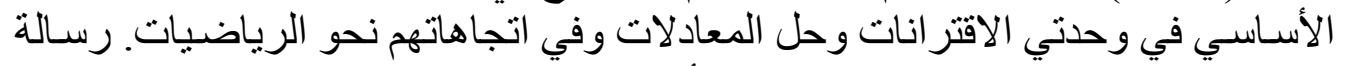

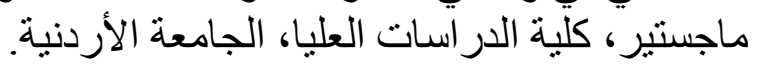

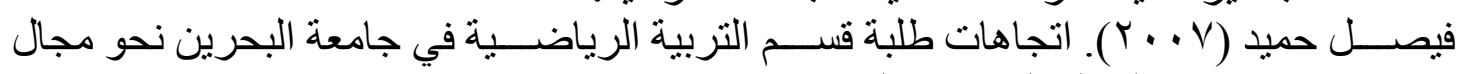

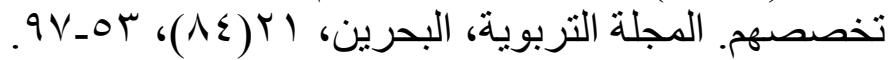

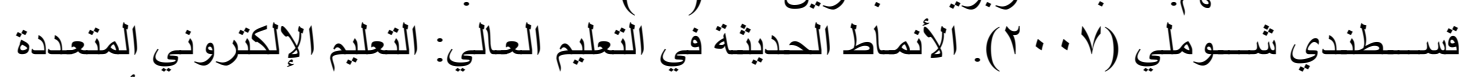

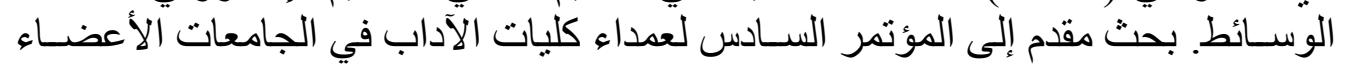


في اتحاد الجامعات العربية (ندوة ضـــــان جودة التعليم والاعتماد الأكاديمي) جامعة

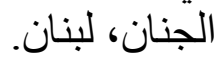

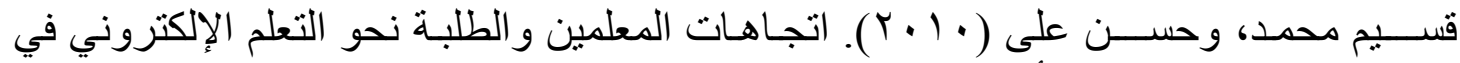

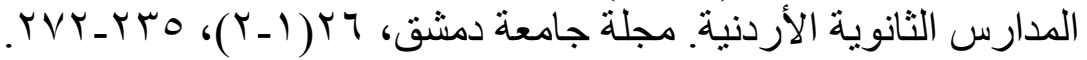

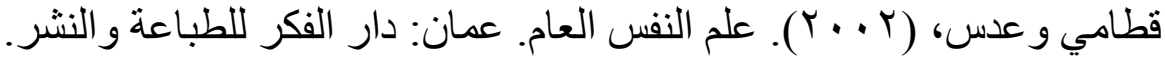

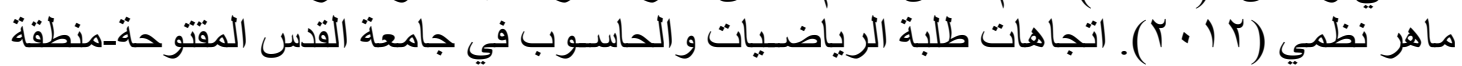

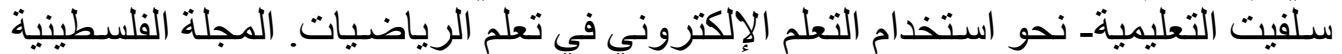

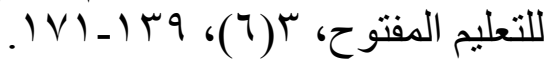

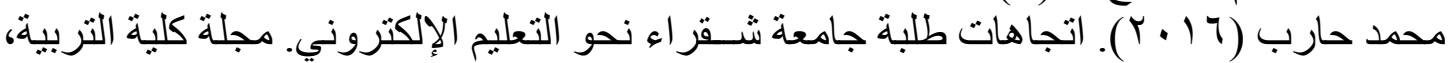

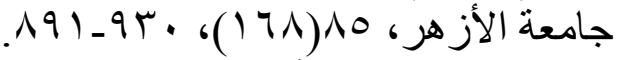

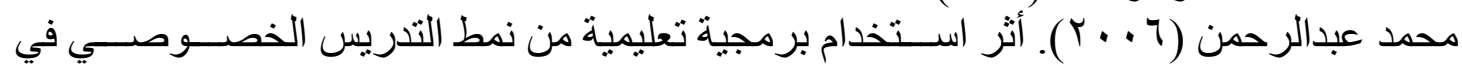

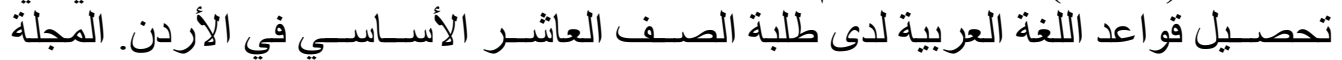

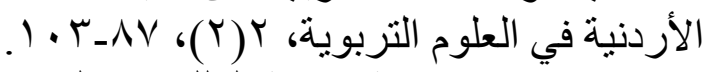

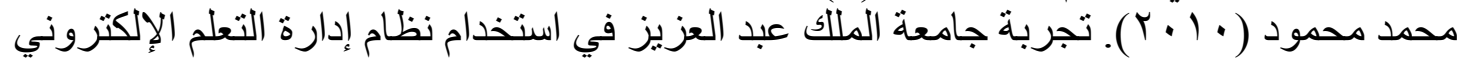
EMES

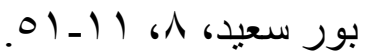

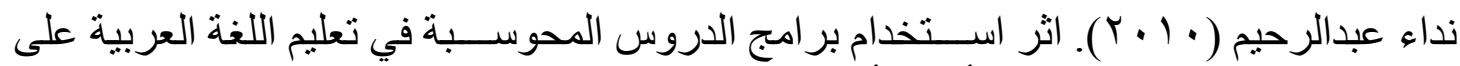

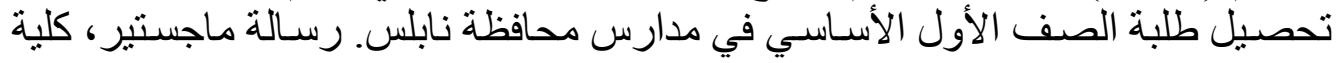
الدراسات العليا، جامعة النجاح، فلسطين.

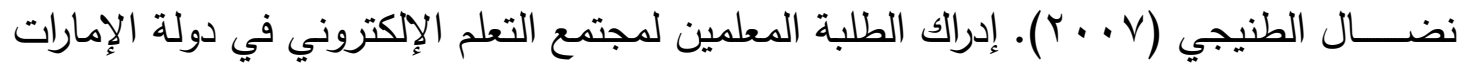

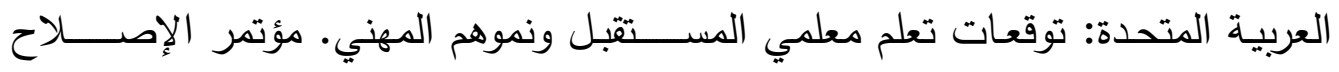
المدرسي: تحديات وطموحات، الإمارات.

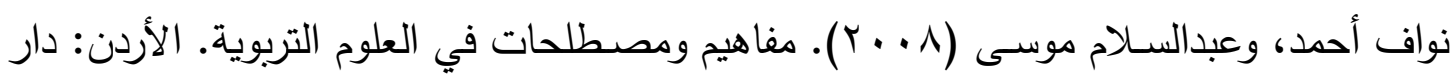

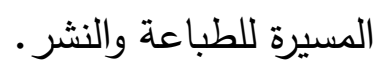

هند عقيل الميزر (r(ب). اتجاهات الطالبات نحو اســـخدام التعلم الإلكتروني في تدريس

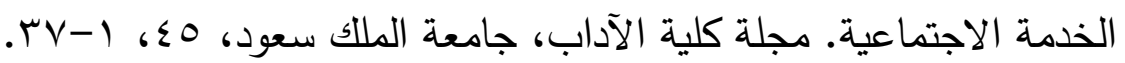

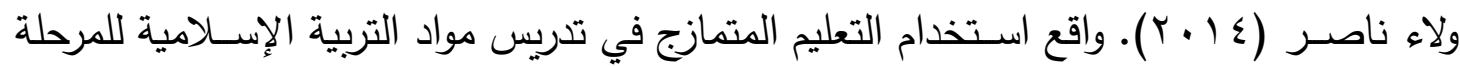
المتوسطة بمدينة جدة. رسالة ماجستير ، كلية التربية، جامعة أم القرى.

\section{ثانيا: المراجع الأجنبية}

Alonso, F., Manrique, D., Martinez, L. \& Vines, J. (2011). How blended learning reduces underachievement in higher education: An experience in teaching computer sciences. IEEE Transactions on Education, 54(3), 471-478.

Cameron, I. (2005). Sustaining motivation in a blended learning environment. Master Thesis. Royal Roads University (Canada).

Driscoll, M. (2002). blended learning: Let's get beyond the hype. ELearning, 3(3), 1-3. 
El-Mansour, B. \& Mupinga, D. (2007). Students' positive and negative experiences in hybrid and online classes. College student journal, $41(1), 242-248$.

Farouk, A. (2013). Tutor's and students' attitudes towards mobile learning in developing country. 3rd international conference for E-Learning $\&$ distance education, Riyadh, Saudi Arabia.

Futch, L. (2006). A study of blended learning at metropolitan research university. DAI-A, 66(10), 15-36.

Hudson, B. (2005). Conditions for achieving communication, interaction and collaboration in E-Learning environments. E-Learning, 15(1), $33-42$.

Liaw, S., Huang, H. \& Chen, G. (2007). Surveying instructor and learner attitudes toward E-learning. Computers \& Education, 49(4), 10661080.

Oliver, M. \& Trigwell, K. (2005). Can be blended learning be redeemed?. E-Learning Journal, 2(1), 17-19.

Poon,J. (2013). An examination of a blended learning approach in the teaching of economics to property and construction students. Property management, 31(1), 39-54.

Vaughan, N. (2007). Perspectives on blended learning in higher education. International Journal on E-Learning, 6(1), 15-21.

Watson, J. (2009). Blended learning: the convergence of online and faceto-face education. USA: North America council for online learning.

Welcker, J. \& Beradino, L. (2006). Blended learning: Understanding the middle ground between traditional classroom and fully online instruction. Journal of Education Technology Systems, 34(1), 33-55. 